Universidad de Talca - Facultad de Ciencias Jurídicas y Sociales

"El estándar de convicción de la duda razonable en el proceso penal chileno, en particular la relevancia del voto disidente"

Raúl Carnevali Rodríguez - Ignacio Castillo Val

\title{
EL ESTÁNDAR DE CONVICCIÓN DE LA DUDA RAZONABLE EN EL PROCESO PENAL CHILENO, EN PARTICULAR LA RELEVANCIA DEL VOTO DISIDENTE*
}

\author{
THE STANDARD OF CONVICTION OF REASONABLE DOUBT IN THE CHILEAN CRIMINAL \\ PROCEDURE, ESPECIALLY REFERRED TO THE RELEVANCE OF A MINORITY VOTE
}

\author{
Raúl Carnevalı RodríGuez ${ }^{* *}$ \\ IgNACIO CASTILLO VAL ${ }^{* * *}$
}

\begin{abstract}
RESUMEN
El sistema procesal penal chileno introdujo un nuevo estándar de convicción para condenar: más allá de toda duda razonable. Éste surge de la tradición jurídica anglosajona, por lo que resulta poco conocido -y bajo cierta interpretación inaplicableen el país, considerando su vinculación con el derecho europeo continental. Por lo mismo, el trabajo pretende dar una mirada distinta al baremo de prueba recogido por nuestro legislador, acercándolo a la discusión que se debería dar en Chile. Además, pretende resolver la siguiente pregunta: ¿es posible condenar sobre la base de que el Tribunal adquirió la convicción más allá de toda duda razonable, en circunstancia de que existe un voto disidente -razonado y motivado-que está por absolver?

\section{ABSTRACT}

The Chilean procedural penal system introduced a new standard of conviction: beyond reasonable doubt. This standard comes from the anglosaxon legal tradition, so it is fairly unknown -and under certain interpretations, inapplicable- in the country, considering chilean link's to European Continental law. Because of this, the following paper strives to provide a different analysis on the standard of evidence used by our lawmakers, bringing it closer to the discussion that should occur in Chile. It also seeks to answer the following question: Is it possible to convict based on the fact that the
\end{abstract}

\footnotetext{
* Una versión preliminar fue presentada, por Raúl Carnevali R., en mayo de 2003, para la Jornada de debate y discusión de la reforma procesal penal, realizada en Antofagasta, organizada por la Defensoría Penal Pública de la II Región y la Universidad de Antofagasta. Quisiéramos agradecer las observaciones formuladas en su momento por el Juez de Garantía Daniel Urrutia Laubreaux y que fueron publicadas en Boletín Centro de Estudios del Derecho, Universidad Católica del Norte, sede Coquimbo, № 4, 2003, pp. 8 y ss. Por último, quisiéramos agradecer especialmente a Danilo Báez, magistrado de Tribunal Oral en lo Penal, por sus rigurosos y asertivos comentarios que, creemos, han servido para mejorar el trabajo. Haberlo logrado, claro está, es nuestra responsabilidad. Trabajo recibido el 21 de julio y aprobado el 27 de septiembre de 2011.

** Doctor en Derecho; Profesor asociado en Derecho Penal de la Universidad de Talca y Director del Centro de Estudios de Derecho Penal de la misma Universidad. Correo electrónico: rcarnevali@utalca.cl.

${ }^{* * *}$ Magister (c) Centro de Estudios de Derecho Penal, Universidad de Talca. Correo electrónico: igcastillo@utalca.cl.
} 
Court was convinced beyond a reasonable doubt, if there is a reasoned and studied minority vote that finds for acquittal?

PaLABRAS Clave

Duda Razonable, Voto Disidente, Absolución Penal

KEY WORDS

Reasonable Doubt, Minority Vote, Criminal Absolution

\section{Aproximación Al PROBlema}

Hoy es un lugar común decir que el nuevo sistema de enjuiciamiento criminal importó un cambio sin precedentes en nuestra cultura jurídica. A través de la reforma procesal penal se introdujeron aspectos como la inmediación, la oralidad, la publicidad, la contradictoriedad, a niveles que se desconocían en nuestra tradición jurídica ${ }^{1}$. De hecho, muchos de esos principios se han replicado -con mayor o menor éxito- en las sucesivas modificaciones a los procesos que se han ido materializando en los últimos años ${ }^{2}$. Dentro de los institutos novedosos de la reforma procesal penal uno que destaca, por su relevancia e importancia política, es el juicio oral. Es en ese escenario donde aquellos principios que señalamos se muestran en su máxima expresión, constituyendo los pilares sobre los cuales se legitima la reforma. Y mucho se ha escrito sobre el juicio oral, desde aspectos teórico-dogmáticos sobre los presupuestos del juicio oral, hasta manuales de litigación para enfrentarlo adecuadamente ${ }^{3}$. Sin embargo, poco se ha reflexionado sobre el estándar de convicción que se adoptó para que el

\footnotetext{
1 Cabe recordar, en todo caso, que previo al nuevo proceso penal estaba vigente en Chile un sistema de enjuiciamiento criminal ortodoxamente inquisitivo, marcado por la escrituración, el secretismo, la mediación, la delegación de funciones y la completa falta de imparcialidad del juzgador. Era un proceso penal en que, en palabras de Ferrajoli, el juez procedía de oficio a la búsqueda, recolección y valoración de las pruebas, llegándose al juicio después de una instrucción escrita y secreta de la que estaban excluidos o, en cualquier caso, limitados la contradicción y los derechos de defensa. FERRAJOLI, Luigi, Derecho y razón. Teoría del garantismo penal, Traducción de Andrés Ibáñez, Perfecto, y Otros, Ed. Trotta, Madrid, 1995, p. 564.

2 Nos referimos, en concreto, a las reformas al procedimiento en materia de Familia y al procedimiento Laboral, en donde se han incorporado, con matices, similares principios que los del proceso penal, en particular, la oralidad, inmediación y concentración.

3 A modo de referencia, cfr., entre otros, Horvitz Lennon, María Inés; López MASLE, Julián, Derecho procesal penal chileno, tomos I y II, Ed. Jurídica, Santiago, 2002 y 2004; DuCE, Mauricio; RieGo, Cristián, Proceso Penal, Ed. Jurídica, Santiago, 2007; Duce, Mauricio; Baytelman, Andrés, Litigación penal en juicios orales, $2^{\circ}$ Edición, Facultad de Ciencias Jurídicas y Sociales, Universidad Diego Portales, Santiago, 2002; VIAL CAMPOS, Pelayo, Técnicas y fundamentos del contraexamen en el proceso penal chileno, Ed. Librotecnia, Santiago, 2006; Carocca, Alex, y Otros, Nuevo proceso penal, Ed. ConoSur Ltda., Santiago, 2000; Blanco SuÁrez, Rafael, y Otros, Litigación estratégica en el nuevo proceso penal, Ed. LexisNexis, Santiago, 2005.
} 
tribunal pudiera condenar a una persona, lo que ha de ser uno de los aspectos centrales del juicio ${ }^{4}$.

Por otra parte, si bien el título del presente trabajo hace referencia a la expresión "convicción", por ser aquella utilizada en el Código Procesal Penal, no se nos escapa la irrefutable crítica a la que ha sido sometida en el último tiempo, y que compartimos. En efecto, por convicción pareciera referirse a un modelo de libre valoración de la prueba por parte del juez, de carácter eminentemente subjetivo, en virtud del cual el adjudicador adquiere el íntimo convencimiento acerca de los hechos ocurridos. Sin embargo, este razonamiento es inconsistente para quienes compartimos un modelo garantista, que permita el control de esa justificación por parte de un tribunal superior o de un tercero, incluida, obviamente, la comunidad. En efecto, la interpretación correcta del Art. 340 del Código Procesal Penal habría que hacerla tomando en consideración los límites prescritos en el Art. 297 del mismo cuerpo adjetivo y, compartiendo con Accatino ${ }^{5}$, mediante una interpretación no subjetivista del estándar de prueba más allá de toda duda razonable. Por eso, no nos parece completamente satisfactorio -porque igualmente deja un espacio incontrolable de subjetivismo-, la posición de Coloma ${ }^{6}$, para quien habría ahí un doble filtro, primero en los límites fijados por los principios de la lógica, las máximas de la experiencia y los conocimientos científicamente afianzados, y segundo, en el convencimiento de los jueces de la realización de la conducta tipificada y de la participación culpable. En todo caso, mediante un proceso de motivación racional, objetiva y dotada de validez intersubjetiva ${ }^{7}$.

\footnotetext{
${ }^{4}$ Entendemos con Gascón, que un estándar de prueba (convicción) supone: "criterios que indican cuándo se ha conseguido la prueba de un hecho; o sea, los criterios que indican cuándo está justificado como verdadera la hipótesis que lo describe" (la cursiva en el original). Gascón ABeLlán, Marina, "Sobre la posibilidad de formular estándares de prueba objetivos", DOXA, Cuadernos de Filosofía del Derecho № 28, 2005, p. 129.

${ }^{5}$ Cfr. Accatino SCaglotti, Daniela, "El modelo legal de justificación de los enunciados probatorios en las sentencias penales y su control a través del recurso de nulidad", en AcCATINO SCAGLIOTTI, Daniela (Coord.), Formación y valoración de la prueba en el proceso penal, Ed. Abeledo Perrot, Santiago, 2010, pp. 119 ss., en especial, pp. 137 ss.; ACCATINO SCAGLIOTTI, Daniela: "La fundamentación de la declaración de hechos probados en el nuevo proceso penal. Un diagnóstico", Revista de Derecho de la Universidad Austral de Chile, Vol. XIX, N. 2, 2006, pp. 9 ss. Similar opinión puede verse en BáEZ, Danilo, “¿Estándar de convicción o arbitrariedad judicial? Bases y propuestas para la interpretación del estándar de "duda razonable" en el Código Procesal Penal", en Verdugo M., Mario (Dir.), Gaceta Jurídica, Doctrinas Esenciales, Derecho Penal, Tomo I, Legal Publishing Chile, Santiago, 2011, pp. 867 y ss.

${ }^{6}$ Coloma Correa, Rodrigo, "Panorama General de la Prueba en el Juicio Oral", en Coloma Correa, Rodrigo (Ed.), La Prueba en el Nuevo Proceso Penal Oral, Ed. LexisNexis, Santiago, 2003, p. 27. Con todo, no podemos dejar de reconocer que el aporte de Coloma ha sido trascendental en esta discusión, pues fue el primero que cuestionó, decididamente, una aproximación enteramente subjetivista al citado baremo.

7 Sobre esto cfr., entre otros, Ferrer Beltrán, Jordi, Prueba y verdad en el derecho, $2^{\circ}$ Edición, Marcial Pons, Madrid, 2005, pp. 80 y ss.; Gascón Abellán, Marina, Los hechos en el derecho, $3^{\circ}$ Edición, Marcial Pons, Madrid, 2010, p 169 y ss.
} 
Como se sabe, el Art. 340 del Código Procesal Penal ${ }^{8}$ introdujo un nuevo estándar de prueba para que el Tribunal pueda dictar una sentencia condenatoria. Este consiste en que el juzgador debe adquirir la convicción más allá de toda duda razonable de que se ha cometido el hecho punible objeto de la acusación y que en él le ha correspondido una participación culpable al acusado.

Se ha insertado pues, en nuestro ordenamiento jurídico, un estándar que, como es conocido, emerge de la tradición jurídica anglosajona y que hasta hace un tiempo era desconocido en la propia cultura del derecho europeo continental, y de la que somos herederos ${ }^{9}$. En Estados Unidos, por ejemplo, el estándar de prueba acerca de la concurrencia de los elementos de la responsabilidad penal en una persona deben ser probados "beyond a reasonabledoubt" y aqueIlo ha sido considerado por la Corte Suprema como un derecho fundamental, reconocido en la propia Constitución, aun cuando aquél no aparezca siquiera mencionado en la carta fundamental ${ }^{10}$.

En todo caso conviene, desde ya, realizar una precisión respecto de los orígenes del estándar de la duda razonable, por cuanto ello puede ser útil para comprender mejor el alcance y sentido que este baremo tiene y que, para bien o para mal, constituye el límite de convicción impuesto por nuestro legislador para condenar a un imputado en un juicio penal.

El estándar de duda razonable, como nos enseña Whitman, descansa en el olvidado mundo de la teología cristiana pre moderna que, por cierto, escasa relevancia le asignaba a nuestras preocupaciones garantistas o epistemológi$\operatorname{cas}^{11}$. En efecto, el estándar de prueba no pretendía proteger al imputado-como hoy lo sostenemos-, sino que la duda razonable fue originalmente concebida para proteger -de su condena- el alma de los integrantes del jurado. Se creía,

\footnotetext{
${ }^{8}$ Art. 340: "Convicción del tribunal. Nadie podrá ser condenado por delito sino cuando el tribunal que lo juzgare adquiriere, más allá de toda duda razonable, la convicción de que realmente se hubiere cometido el hecho punible objeto de la acusación y que en él hubiere correspondido al acusado una participación culpable y penada por la ley. El tribunal formará su convicción sobre la base de la prueba producida durante el juicio oral. No se podrá condenar a una persona con el solo mérito de su propia declaración".

${ }^{9}$ No se nos escapa que en Inglaterra, por ejemplo, se ha ido abandonando el estándar de duda razonable y se ha ido imponiendo, en su lugar, un estándar de firme convicción. LaUDAN, Larry, "Por qué un estándar de prueba subjetivo y ambiguo no es un estándar", Traducción de Calvo Soler, Raúl, DOXA, Cuadernos de Filosofía del Derecho, № 28, 2005, p. 100.

${ }^{10}$ In Re Winship, 397 U.S. 358, 374 (1970). En ese sentido la jurisprudencia de la Corte Suprema de Estados Unidos se ha mantenido bastante inalterable, en términos de entender que el estándar de prueba del proceso penal, el de la duda razonable, se encuentra consagrado en la sexta enmienda. Así se ha dicho, entre otros, en los siguientes fallos: Jones v. United States, 526 U.S. 227 (1999); Apprendi v. New Jersey, 530 U.S. 466 (2000); Ring v. Arizona, 536 U.S. 584 (2002) y Cunningham v. California 549 U.S. 270 (2007).

${ }^{11}$ Whitman, James, The Origins of Reasonable Doubt, Theological roots of the criminal trial, Yale University Press, New Haven, 2008, p. 2.
} 
en esos tiempos, que el destino de quienes juzgaban estaba también en juego en cada juicio, porque condenar a un inocente era considerado en la antigua tradición cristiana potencialmente como un pecado capital. Por ende, la duda razonable fue en un inicio creación de la doctrina teológica, que procuraba asegurar -o reafirmar- en el jurado la idea de que ellos podían condenar al imputado sin poner en riesgo su propia salvación, siempre y cuando las dudas de la responsabilidad del acusado no fueran razonables ${ }^{12}$.

Con todo, el estándar de la duda razonable no fue utilizado en el proceso penal ordinario sino hasta finales del siglo XVIII, principalmente, en una serie de casos de alta traición en Irlanda (1798); aun cuando algunos observan sus primeras manifestaciones en ciertos juicios en Massachusetts, una década antes ${ }^{13}$. Con anterioridad a esos casos, no existía en el derecho anglosajón un estándar de prueba definido para que el jurado considerara condenar a un imputado y, a decir verdad, el estándar no parecía realmente alto $^{14}$. Es más, en aquella época la máxima no era que un imputado se consideraba inocente mientras no se probara, más allá de toda duda razonable, que había cometido el delito, sino que si él era inocente debía estar en condiciones de convencer al jurado por la calidad y características de su refutación a la evidencia del persecutor ${ }^{15}$.

Las primeras referencias a la duda razonable, como ya dijimos, aparecieron a finales del siglo XVIII, en varias instrucciones de los jueces al jurado, entre las que destacan las siguientes: "Si apreciando las evidencias presentadas, mantiene alguna duda razonable... él (imputado) tiene derecho a su absolución", "Si usted tiene alguna duda, usted debe absolverlo", "Si usted tiene dudas sobre el caso, por supuesto que debe absolver al prisionero", "Si hay una duda razonable, en ese caso esa duda debe ser decidida a favor del prisionero", "Si usted ve cualquier duda razonable, usted debe absolverlo"16. En todo caso, lo que se observa, a decir del propio Langbein, es que mientras el proceso penal anglosajón fue fortaleciendo sus características de adversarialidad, con la cre-

\footnotetext{
${ }^{12}$ Whitman, The Origins, cit. nota n. 11, p. 2. Por lo mismo, y en lo relevante para nuestro trabajo, el estándar de duda razonable - en la tradición del Common Law- no fue creado desde una perspectiva epistemológica (que nosotros sostenemos) ni necesariamente desde una perspectiva consensuada o narrativa (que sostienen otros) sino que por una motivación religiosa de protección del jurado. Por lo mismo, nada impide que hoy -desaparecidas esas razones- podamos indagar el sentido y alcance de aquel baremo que más se adecue a nuestro Estado democrático de Derecho.

13 Parecen compartir el momento histórico del surgimiento en el proceso laico del estándar de convicción de la duda razonable, Horvitz; López, Derecho Procesal, Tomo II, cit. nota n. 3, p. 154.

${ }^{14}$ LangBein, John, The origins of adversary criminal trial, Oxford University Press, Oxford, 2005, p. 262.

15 Beattie, John, Crime and the Courts in England 1660 - 1800, citado en LANGBein, The origins of ADVERSARY, CIT. NOTA N. 14, P. 263.

${ }^{16}$ Beattie, John, Crime and the Courts in England 1660 - 1800, citado en LangBein, The origins of adversary, cit. nota n. 14, pp. 263 y 264 (la traducción es nuestra).
} 
ciente participación del defensor; la imparcialidad del juez; el desarrollo de las técnicas de litigación, y especialmente por la preocupación respecto de la posibilidad de una condena errónea y la necesidad de establecer un límite a la persecución penal, se fue generando el camino fértil para el desarrollo del estándar de la duda razonable.

Como se aprecia, el origen y desarrollo del estándar de duda razonable -desde una perspectiva eclesiástica y laica-, pareciera ser antinómico con las expectativas que -siguiendo a Taruffo- uno debería exigir de un estándar probatorio suficiente para condenar penalmente a un ciudadano. En efecto, el estándar adquiría una relevancia simbólica respecto del jurado (en el ámbito eclesiástico) o bien, se sustentaba sobre una lógica subjetiva, apreciada holísticamente y en el sentido de una narración o historia (storytelling) en el caso del juicio ordinario ${ }^{17}$. Pero ello no debe sorprender, porque el proceso de adjudicación en el juicio oral, propio del modelo anglosajón, descansó siempre en la participación de un jurado lego, exento de la obligación de motivación. Esta no es, en cambio, nuestra realidad -y por el momento creemos que no debería serla-, pues nosotros tenemos un sistema procesal penal que descansa en la decisión de adjudicación en un tribunal colegiado de derecho, que tiene una pretensión epistemológica, y que además tiene la obligación de motivar. Esto, necesariamente, debería llevar a una interpretación diferente del baremo, con consecuencias distintas en las decisiones de mayoría. Ese es el objetivo de este trabajo como se verá más adelante.

En este sentido, no deja de ser interesante, y en cierto grado motiva el presente trabajo, el esfuerzo de Taruffo por intentar justificar cómo aquel baremo (el de la duda razonable), aplicado en el derecho europeo continental (Civil Law) puede tener cierto éxito, por estar sometido a jueces profesionales, con obligación de apreciar la prueba analíticamente y, por sobre todo, con el deber de motivar y justificar su valoración. El valor ético-político que el autor le

\footnotetext{
17 Duce y Riego parecen sostener, en nuestro medio, una clásica aproximación narrativa o storytelling, que se centra en el concepto de plausibilidad como criterio de verificabilidad probatoria. Cfr. DucE; Riego, Proceso Penal, cit. nota n. 3, pp. 497 y ss. Cabe recordar, como afirma Taruffo, que toda la teoría de la denominada storytelling, es elaborada en el plano del análisis psicológico del comportamiento de los jurados. Así y todo, si fuera ese en definitiva el modelo adoptado por los jurados, lo cierto es que compartimos con el autor italiano que aquello sería una profunda y errada modalidad de decisión, por cuanto prescinde de la valoración de la credibilidad de cada una de las pruebas y no se preocupa por establecer qué hechos han sido demostrados y qué hechos no lo han sido; además de ser cuanto menos genérico, cultural y subjetivamente relativo y carente de toda garantía de objetividad. Pero también, por su cercanía con el concepto de verosimilitud, donde aquello que es plausible sería verosímil y lo sería no aquello que es verdadero, si no aquello que parece corresponderse con la normalidad. TARUfFo, Michele, "Tres observaciones sobre 'Por qué un estándar de prueba subjetivo y ambiguo no es un estándar', de Larry Laudan", Traducción de Ferrer Beltrán, Jordi, DOXA, Cuadernos de Filosofía del Derecho, № 28, 2005, p. 122. Si eso sucede en Chile, donde además tenemos jueces profesionales, la cuestión sería lamentable.
} 
asigna al estándar es, a nuestro juicio, lo que justifica tal empresa. Volveremos sobre ello infra ${ }^{18}$.

Dicho lo anterior, nos parece necesario afirmar que compartimos el análisis más o menos generalizado en nuestra doctrina, en cuanto a que el carácter foráneo a nuestra tradición, del baremo de prueba, no es motivo suficiente para emitir un juicio negativo sobre su introducción en nuestro sistema procesal penal ${ }^{19}$. Sin embargo, creemos que si se profundiza acerca de su incorporación, debe estimarse inconsistente e incoherente con la eventual hipótesis del voto disidente respecto de la decisión de los hechos, conforme se ha ido asentando en nuestra jurisprudencia. En términos sencillos, y según se fundamentará, un voto disidente respecto de la quaestio facti, motivado y razonado -y por lo mismo no subjetivo- conforme las exigencias de nuestro proceso penal, en virtud del cual uno de los jueces del tribunal ha considerado que existe una duda razonable de que realmente se hubiere cometido el hecho punible y que en él hubiere correspondido al acusado participación culpable, debe ser suficiente para absolver al imputado. Si nuestro proceso penal tiene una pretensión de búsqueda de verdad -epistémica, no formal como equivocadamente se sostiene- como legitimación del castigo estatal, aquella debe ser impuesta cuando -al menos desde una perspectiva material-, existe unanimidad de los jueces en cuanto a la condena.

Por de pronto, como se verá, la incorporación de la duda razonable en el Código Procesal Penal chileno recién aconteció al final del debate legislativo, prácticamente cuando faltaban escasos meses para que la reforma comenzara a funcionar en su primera etapa -diciembre de 2000. Sin mayor discusión, se dispuso como criterio para precisar un grado de convicción que debe alcanzar el juez al momento de sentenciar. No obstante, en ese momento legislativo poco se profundizó acerca de su origen y sobre su sentido dentro del sistema procesal del que emana, esto es, del Common $\operatorname{Law}^{20}$. Y es que, como se observará, el estándar de más allá de toda duda razonable -beyond a reasonable

18 Cfr. Taruffo, "Tres observaciones", cit. nota n. 17, pp.115 ss.; Taruffo, Michele, "Conocimiento Científico y Estándares de Prueba Judicial", en La Prueba, Artículos y Conferencias, Editorial Metropolitana, Santiago, 2009, pp. 87 ss.

${ }^{19}$ Más bien las críticas pueden ir por su excesivo subjetivismo, su indefinición y su excesivo contenido probabilístico. Todas estas críticas se resumen en lo que Taruffo denomina una "necesidad insatisfecha de objetividad" en la determinación judicial de los hechos. TARUFFO, "Tres observaciones", cit. nota n. 17, p. 116.

${ }^{20}$ Una opinión similar puede verse en Báez, "¿Estándar de convicción o arbitrariedad judicial?", cit. nota n. 5, p. 852. El autor citado apunta a que la falta de profundización y discusión en el Parlamento respecto del estándar de convicción -sumado a una precariedad de diálogo dogmático por parte de la doctrina nacional- "han llevado en la actualidad a un estado de completa incertidumbre y peligrosidad en relación a la forma de interpretación de la noción de duda razonable que se emplea en los distintos tribunales nacionales" (destacado en el original). 
doubt- se entiende también como una exigencia dirigida al acusador en cuanto a la calidad de su prueba ${ }^{21}$. Es por ello, que en estos casos también se habla de Burden of Proof, es decir carga de la prueba -onus probandi-. Si las evidencias aportadas por el órgano persecutor no alcanzan la medida o el estándar de más allá de toda duda razonable, no es posible condenar. En consecuencia, es una exigencia dirigida también a quien persigue, y no sólo a quien juzga, como parece entenderse en Chile ${ }^{22}$.

Quisiéramos advertir que el tema central de este trabajo no será el examen particular del estándar en comento, las profundas críticas de las que ha sido objeto, ni cuáles son sus particularidades en el Derecho norteamericano -aunque serán expuestas de forma sucinta-, sino los problemas que se pueden presentar en nuestro país con su inclusión, en especial cuando se está frente a un voto disidente. Así, por ejemplo, ¿es admisible condenar argumentando que el Tribunal ha adquirido la convicción más allá de toda duda razonable, en circunstancias de que existe un voto disidente -razonado y motivado conforme lo exige el legislador- que está por absolver? La cuestión, como se ha adelantado, es la siguiente: si para uno de los miembros del Tribunal oral las pruebas aportadas por el persecutor, valoradas conforme a la sana crítica, mediante un

\footnotetext{
${ }^{21}$ Park, Roger; Leonard, David P.; GoldberG, Steven H., Evidence Law., West Group, Saint Paul, MN, 1998, pp. 88 ss.; ChIESA APONTE, Ernesto, Derecho procesal penal de Puerto Rico y Estados Unidos, Editorial Forum, Bogotá, Vol. II, 995, pp. 51 ss. A nuestro juicio, la errada interpretación se ha generado, entre otras razones, porque en Chile no se ha distinguido entre el "prosecution's production burden" y el "prosecution's burden of persuasion". Mientras el primero define el estándar de producción de prueba necesario para poder juzgar a una persona, el segundo da cuenta del estándar requerido para poder persuadir a otro -al juez- de que aquellos elementos probatorios son suficientes para condenar a alguien. En nuestro país, dado que el juez de garantía hace más bien un control de legalidad de la acusación -y no de mérito-, el primer estándar queda entregado casi exclusivamente -salvo en alguna hipótesis de sobreseimiento definitivo- al Ministerio Público, y el segundo queda reservado al tribunal, mediante el estándar de la duda razonable. Cfr. LANGBEIN, The origins of adversary, cit. nota n. 14, pp. 258 ss. Lo mismo en HeNDler, Edmundo, Derecho penal y procesal penal, Ed. Ad-Hoc, Buenos Aires, 1996, pp. 212 ss.

22 Por lo mismo debe considerarse lo dispuesto en el presente trabajo no sólo respecto del Ministerio Público, sino también respecto del querellante, sea que actúa en compañía del órgano estatal, o privadamente por medio del instituto del forzamiento de la acusación (art. 258 del Código Procesal Penal). No es posible extendernos sobre este punto, pero es evidente que el estándar de prueba sugerido por nuestro Código Procesal Penal también presenta diferencias estructurales con la existencia de la figura del querellante y, con mayor razón, con la del forzamiento de la acusación. En efecto, la duda razonable se enmarca dentro de un contexto en que, evidentemente, es el Estado el que tiene la carga de la prueba en contra del imputado, pues ello justifica el desequilibrio que encierra la presunción de inocencia y el ejercicio del principio in dubio pro reo, lo que no es claro en una contienda entre particulares. No parece suficiente, en este punto, decir que la presunción de inocencia y el in dubio pro reo se justifican por el riesgo inherente a ciertos valores sociales (libertad) que encierra la respuesta penal, porque cuando el juicio es entre particulares (víctima e imputado) aquello no parece razón para que una, la víctima, quede en una posición tan desmejorada frente al otro, el imputado. Por eso el juicio penal debe siempre ser, necesariamente, entre el Estado y el acusado.
} 
sistema de libertad probatoria y con la obligada motivación ${ }^{23}$, no superan el umbral que permita adquirir la convicción más allá de toda duda razonable, ya sea de la existencia del hecho punible o de la participación culpable, es posible aseverar entonces, que existen dudas razonables sobre aquellos puntos y, por tanto, que las pruebas no habrían sido suficientes como para revertir la presunción de inocencia ${ }^{24}$. Parece pues, que habría una incoherencia entre la existencia de un voto disidente -que obviamente debería satisfacer lo dispuesto en el Art. 297 del Código Procesal Penal-y que se condene argumentando que la mayoría -los otros dos jueces- sí habría adquirido la convicción más allá de toda duda razonable ${ }^{25}$.

Antes de explicar nuestro parecer al respecto, revisaremos brevemente el sentido y alcance de la verdad en el nuevo proceso penal y expondremos cuál fue nuestra historia legislativa en torno al estándar de duda razonable, a fin de comprender cómo se llegó a incorporar dicho baremo adjudicador. A continuación, discurriremos sobre los niveles de convicción exigidos en el antiguo sistema procesal, todo ello a fin de disponer de los elementos de juicio que permitan valorar la incorporación de este nuevo concepto. Para luego, conocer las particularidades más sobresalientes de lo que es la duda razonable, considerando para este efecto, algunos conceptos que se emplean en la esfera del Common Law. Por último, terminaremos con nuestra visión y propuesta respecto de la problemática que surge de la existencia del voto disidente, en lo que a quaestio facti se refiere, y las posibles soluciones.

\section{Algunos alcances sobre la verdad COMO PRESUPUESTO DE LA DUDA RAZONABLE}

El presente apartado del trabajo no pretende hacer una revisión acabada sobre los alcances epistemológicos del proceso penal, tampoco discurriremos acerca de si es o no posible alcanzar una verdad en el juicio penal, y de ser así, cuál debiera ser. Lo nuestro es más modesto, queremos simplemente esbozar

23 En el mismo sentido, BÁEZ, "¿Estándar de convicción o arbitrariedad judicial?", cit. nota n. 5, p. 854.

${ }^{24}$ Compartimos, en todo caso, con Laudan, la idea que con un adecuado estándar de prueba, por ejemplo el de la duda razonable (siempre que sea objetivo y razonado) la presunción de inocencia material dejaría de tener sentido en el juicio, porque aquella no sería necesaria ni apropiada. Lo relevante, entonces, sería que el adjudicador sea particularmente exigente en que la culpabilidad del imputado debe ser probada en el juicio, y que la única prueba relevante para su culpabilidad o inocencia es la prueba que será producida en el juicio. Cfr. LAUDAN, "Por qué un estándar de prueba subjetivo", cit. nota n. 9, p. 112.

${ }^{25}$ En términos similares, EtCheberRY, Alfredo, "Consideración sobre el criterio de condena en el Código Procesal Penal", en Delito, pena y proceso. Libro Homenaje a la memoria de Tito Solari Peralta, Editorial Jurídica de Chile, Santiago, 2008, pp. 677-678. 
algunas ideas respecto del sentido y alcance que pudiera tener la verdad en el proceso penal y cómo se relaciona con la duda razonable, en el contexto de un proceso adversarial.

Lo primero que uno debe decir, respecto de esto, es que el proceso penal -aunque necesariamente orientado a la averiguación de la verdad $-{ }^{26}$ difícilmente puede pretender siempre alcanzarla y, por el contrario, no son pocas las veces que se cometen importantes errores ${ }^{27}$. Los jueces, como en cualquier actividad humana, se equivocan en sus decisiones y condenan a una persona inocente o absuelven a una que efectivamente cometió el delito. Es por ello que, al decir de Taruffo, el proceso penal "no está particularmente interesado de forma general en la reducción o la eliminación de los errores, sino que tiende a distribuir los errores de forma tal que favorezcan sistemáticamente a la posición del imputado"28. Dicho de otra manera, el proceso penal no está -difícilmente

${ }^{26}$ Por lo mismo no compartimos con quienes consideran que el proceso adversarial o acusatorio está
más bien dirigido a la implementación del principio de contradicción entre las partes, y al respeto por
la autonomía y derechos del imputado (por ejemplo, para evitar la tortura), y dejan en cambio a la
determinación de la verdad sobre los hechos como una mera casualidad (incluso propugnando rebaja
de estándares) que, por sí sola, no es considerara relevante. Una posición similar a la expuesta en Chile
cfr. DucE; RIEGO, Proceso Penal, cit. nota n. 3, pp. 483 ss. En efecto, en opinión de los autores, "este
escenario [del nuevo proceso penal] de protección del imputado en su autonomía para declarar o no,
pone al sistema en la necesidad de privilegiar altamente el funcionamiento de la prueba indiciaria,
esto es, de pruebas que nos permiten reconstruir los hechos sólo parcialmente y que para completar la
verdad de lo ocurrido nos obligan a recurrir al razonamiento deductivo". Sobre lo expuesto, dos cosas.
Primero, no parece razonable justificar -O al menos requiere bastante más carga argumentativa que la
propuesta por los autores- que sea posible rebajar la pretensión de verdad por una mayor protección
del imputado y, segundo, que no es el razonamiento deductivo el método adecuado para "completar
la verdad" del proceso. Al respecto, cfr. Horvitz; LópEz, Derecho Procesal, Tomo II, cit. nota n. 3, p.
333. AtIENZA, Manuel, Las Razones del Derecho, teorias de la argumentación jurídica, Universidad Nacional Autónoma de México, México D.F., 2005.

27 Se podrá sostener, de una manera algo simplista, que la pretensión del tribunal es alcanzar una verdad procesal, formal o "del proceso" y que aquélla no tiene relación con la verdad material. Que, por ello, los jueces entonces no cometen errores, son infalibles, y que su decisión fija una determinada verdad procesal dada la autoridad jurisdiccional de la que están revestidos. Parece evidente que detrás de esa reflexión se esconde un discurso autoritario e infalible difícilmente justificable que, en cuanto a la verdad, parece discurrir más en la lógica del auctoritas, non veritas facit iudicium, más que, como propone Ferrajoli un veritas, non auctoritas faci tiudicium. Cfr. FerRaJol, Derecho y Razón, cit. nota n. 1, p. 37, en el mismo sentido, Ferrajol, Luigi, "Notas Críticas y Autocríticas en Torno a la Discusión Sobre Derecho y Razón", Traducción de Guzmán, Nicolás, Revista de Ciencias Jurídicas Más Derecho 2001/II, p. 38.

${ }^{28}$ Cfr. TARuffo, "Tres observaciones", cit. nota n. 17, p. 117; Cfr. BAyón, Juan Carlos. "Epistemología, moral y prueba de los hechos: hacia un enfoque no benthamiano". En:http://www.udg.edu/ LinkClick. aspx?fileticket=fYVRM58p9Z4\%3D\&tabid=9724\&language=en-US[visitado el 03/06/2011]. Hay, por ende, detrás de esta posición una decisión política y moral de evitar que los errores en la valoración de los hechos perjudique al imputado inocente. Una opinión similar se puede observar en el razonamiento de la Corte Suprema de Estados Unidos cuando, en el caso Addington v. Texas, sostiene que "In a criminal case, on the other hand, the interests of the defendant are of such magnitude that historically and without any explicit constitutional requirement they have been protected by standards of proof 
pudiera estarlo- encaminado a reducir o eliminar los errores, como sería la posibilidad de condenar a un inocente o absolver a un culpable. El proceso, en cambio, pretende distribuir los errores para favorecer la posición del imputado -por ejemplo, con un alto estándar de convicción- y así asegurar que, en caso de error, ello tienda en general a perjudicar a la parte acusadora. Si eso es así, parece entonces evidente que un voto de minoría adecuada y legalmente motivado, debería erigirse como la piedra angular de esa distribución de errores.

Por lo mismo, para Maier: "La averiguación de la verdad, como base para la administración de justicia penal, constituye una meta general del procedimiento, pero ella cede, hasta tolerar la eventual ineficacia del procedimiento para alcanzarla, frente a ciertos resguardos para la seguridad individual que impiden arribar a la verdad por algunos caminos posibles, reñidos con el concepto de Estado de Derecho. Según se advierte, se trata de convertir un principio absoluto en uno relativo, pues reconoce principios superiores que, en ocasiones, hasta lo anulan, v.gr., cuando, en el caso, entran en conflicto o colisionan con aquél" ${ }^{29}$.

Esto no quiere decir, en todo caso, que el proceso penal deba renunciar, por principio y desde un principio, a la búsqueda de la verdad ontológica, sino que, como sostiene Muñoz Conde, debe hacerlo "atemperando esa meta a las limitaciones que se derivan no sólo de las propias leyes del conocimiento, sino de los derechos fundamentales reconocidos en la Constitución y de las normas, formalidades e "impurezas" del proceso penal" ${ }^{30}$. Y cuando se señala que el proceso penal lo que hace es distribuir los errores de manera que favorezcan sistemáticamente al imputado, lo que se quiere decir, precisamente, es que el desequilibrio propio que existe entre las partes de un proceso penal es una condición necesaria para el debido respeto a la presunción de inocencia ${ }^{31}$. Aquella es, como se sabe, una regla de juicio de acuerdo con la cual el juez

designed to exclude as nearly as possible the likelihood of an erroneous judgment. In the administration of criminal justice, our society imposes almost the entire risk of error upon itself. This is accomplished by requiring under the Due Process Clause that the state prove the guilt of an accused beyond a reasonable doubt". Addington v. Texas, 441 U.S. 418 (1979). (Lo destacado es nuestro).

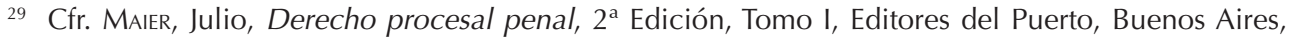
2002, p. 664. Esto es lo que Bayón denomina criterios contra epistémicos, porque introducirían excepciones o desviaciones de diversos tipos respecto a lo que resultaría de seguir incondicionalmente los criterios generales de racionalidad epistémica. Cfr. BAYÓN, "Epistemología, moral y prueba de los hechos", cit. nota n. 28, p. 7.

${ }^{30}$ Cfr. Muñoz Conde, Francisco, La búsqueda de la verdad en el proceso penal, $3^{\text {a }}$ Edición, Hammurabi, Buenos Aires, 2007, p. 111.

31 En el mismo sentido, Muñoz Conde, para quien la tarea de averiguación de la verdad en el proceso penal resulta una tarea altamente compleja, porque en el marco institucional donde se desarrolla la búsqueda de esa verdad, el proceso penal, las partes no están situadas en un plano de igualdad. MuÑoz Conde, La búsqueda, cit. nota n. 30, p. 109. 
debe resolver pro reo la eventual duda que subsista cuando todas las pruebas hayan sido analizadas ${ }^{32}$. Por eso, a decir de Taruffo, un estándar como el de la duda razonable debiera alcanzarse sólo en el caso de que la prueba haya ofrecido la "certeza" sobre los hechos materia de la acusación ${ }^{33}$.

Lo que subyace a esto, entonces, es ese desequilibrio sistemático que se materializa en el estándar de prueba más allá de toda duda razonable en cuanto es una decisión ética o ética-política del Estado, que pretende que el juez penal pueda condenar al imputado solamente cuando haya alcanzado la "certeza" jurídica de su culpabilidad ${ }^{34}$. Ese estándar de prueba, como se ha dicho, es particularmente elevado, por lo pronto, mucho más alto que el de sede civil, porque, a decir de Taruffo, en el proceso penal entran en juego las garantías a favor del imputado, que no tienen un equivalente en el proceso civil ${ }^{35}$. Volvemos a reiterar, si la regulación de un estándar de prueba como el de la duda razonable-particularmente alto-se vincula directamente con una decisión ética o ética-política del Estado, que pretende distribuir errores de manera tal que favorezcan al imputado, parece ilógico que en lo central de la adjudicación, a saber, el estándar de convicción -y su vinculación epistemológica hacia la verdad-se difumine esa distribución, permitiendo la condena con una decisión sólo de mayoría.

Por otra parte, Grande, siguiendo a Damaska -quien centra su análisis más que en la dicotomía entre sistema inquisitivo $\mathrm{v} / \mathrm{s}$ adversarial, en el rol que se le asigna a las partes, por sobre el juez, en la búsqueda de la verdad-, nos su-

\footnotetext{
${ }^{32}$ TARUfFo, Michele, "Algunos comentarios sobre la valoración de la prueba", en La Prueba, Artículos y Conferencias, Editorial Metropolitana, Santiago, 2009, p. 36. Es por ello que para Taruffo, ese desequilibrio estructural no se da en el proceso civil, en el cual las partes se ubican sistemáticamente en un mismo nivel.

${ }^{33}$ TARUfFo, "Algunos comentarios", cit. nota n. 32, p. 37. Con todo, habría que precisar que el estándar de duda razonable no exige "certeza", por el contrario, la adopción del estándar de duda razonable constituye una manifestación expresa en rechazo a tal nivel de convicción. En términos sencillos, el estándar de prueba adoptado por nuestro legislador supone la existencia -y la acepta- de errores en la adjudicación y, por lo mismo, asume que el Ministerio Público no debe superar todo tipo de errores. Sin embargo, en la adopción del estándar de duda razonable subyace la pretensión de que existan más absoluciones erróneas que condenas erróneas. La lógica que se encuentra detrás, en otras palabras, es que mientras más alto es el estándar de prueba para el Ministerio Público, menos probabilidades de condenar a un inocente.

${ }^{34}$ TARuffo, "Conocimiento Científico", cit. nota n. 18, p. 113.

${ }^{35}$ Estos principios, a saber, la presunción de inocencia, el in dubio pro reo, la idea de que es la acusación la que tiene la carga de la prueba, y el estándar de prueba (en nuestro caso el estándar de duda razonable), forman parte de lo que Laudan denomina el núcleo débil de la epistemología jurídica, por cuanto permiten -mediante la epistemología- ayudar en la distribución correcta de errores que, socialmente, aparecen como aceptables en un proceso penal. Cfr. LaUDAN, "Por qué un estándar de prueba subjetivo", cit. nota n. 9, p. 97; LAUDAN, Larry: Truth, Error, and Criminal Law, and Essay in Legal Epistemology, Cambridge Studies in Philosophy and Law, Cambridge, 2006, p 29.
} 
giere que en el sistema anglosajón (Common Law) la búsqueda de la verdad es entregada a las partes, quienes definen el horizonte de proyección del debate, en oposición al modelo continental donde la búsqueda de la verdad es responsabilidad de la autoridad, del juez. En estas dos visiones, descansa, como es obvio, una determinada aproximación ideológica hacia la indagación y el establecimiento de la verdad. En esa perspectiva, como señala la citada autora, más allá de la cuestión estereotipada acerca de una supuesta mayor cercanía hacia la verdad de un sistema sobre otro, lo que hay en el fondo, en cuanto a diferencias sistémicas, es lo referente a los mecanismos y reglas que el sistema establece para la averiguación de la verdad, y la "coherencia" al definir qué tipo de verdad es la que se desea encontrar por medio del procedimiento ${ }^{36}$.

En ese sentido, el sistema inquisitivo pareciera buscar una verdad objetiva (material) que, en realidad, se aproxima a un ideal de verdad ontológica, basada en la creencia de que la búsqueda de una verdad objetiva no solamente es posible, sino que, además, deseable. En base a ese presupuesto, entonces, el juez, como responsable de la averiguación de la verdad, y la determinación de la inocencia o culpabilidad del imputado, debe desarrollar la actividad de la prueba orientado hacia esa verdad material. Por ello, la justicia en el sistema inquisitivo se entiende alcanzada cuando se logra objetiva, sustancial y ontológicamente la verdad material.

El modelo adversarial, por otro lado, parte de una premisa básica distinta, a saber, que no es posible alcanzar esa verdad ontológica por un tercero "imparcial", el juez, justamente, porque en ese escenario es imposible serlo. Aun cuando el juez sea genuinamente imparcial, inevitablemente desde el comienzo de la investigación se va a generar una hipótesis que va a intentar corroborar. Como resultado, entonces, del reconocimiento de estas limitaciones cognitivas, el modelo adversarial evita que un tercero reconstruya una determinada verdad, por su carácter prejuicioso y, en cambio, opera sobre la lógica de las prácticas cognitivas ordinarias, a saber, a través de una confrontación entre dos partes, cada una de ellas sosteniendo una distinta verdad frente a un tercero adjudicador $^{37}$. Sin embargo, ello no debería suponer, en lo absoluto, que deba renunciarse a buscar la verdad en el juicio.

Lo importante, a nuestro juicio, es superar, como sea, antiguas concepciones, Ilevadas a la práctica durante siglos, que propiciaban -y como hemos visto, aún propician- la búsqueda de la verdad a toda costa, sin importar el recurso a los tormentos y al método inquisitivo a ultranza. Sostenemos que la investigación de

${ }^{36}$ Grande, Elisabeta, "Dances of Criminal Justice: Thougths on Systemic Differences and the Search for the Truth", en JACKSON, John y Otros, Crime, Procedure and Evidence in a Comparative and International Context, Essays in Honour of Professor MirjanDamaska, Hart Publishing, Oxford, 2008, pp. 145 y ss.

${ }^{37}$ Grande, "Dances of Criminal Justice",cit. nota n. 36, p. 147 
la verdad en el actual proceso penal no es un valor absoluto -en ciertos casos, quizás ni siquiera posible-, sino que se halla limitada por los valores éticos y jurídicos del Estado de Derecho ${ }^{38}$.

En ese estado actual, el modelo acusatorio, pareciera discurrir sobre la idea de que existen otros valores y principios en juego en la persecución penal, los que, en no pocas ocasiones, ponen un límite, obstaculizan la averiguación de la verdad histórica respecto del delito investigado ${ }^{39}$. La reforma procesal penal, en ese sentido, constituye un cambio paradigmático en nuestro sistema de enjuiciamiento criminal, pues introdujo importantes modificaciones en las relaciones Estado-individuo, estableciendo que las garantías de los derechos fundamentales de los participantes en el juicio penal, como derivación del principio acusatorio, se convierten en un límite fundamental al ejercicio del poder punitivo ${ }^{40}$. En la misma línea, por ende, se sustenta el estándar de prueba prescrito por nuestro legislador, a saber, el de la duda razonable.

Hoy existe consenso, creemos, en que la búsqueda de la verdad -aquella que se obtiene cuando los culpables son condenados y los inocentes son absueltos- es un objetivo relevante en nuestro sistema de justicia criminal ${ }^{41}$. Por eso el sistema procesal penal -con los límites que, en general, están establecidos a favor del imputado- debería avanzar en la dirección de buscar una verdad -y nada más que la verdad- respetuosa de las garantías fundamentales.

\footnotetext{
${ }^{38}$ De Urbano, Eduardo; Torres, Miguel Angel: La Prueba llícita Penal, Ed. Thomson Aranzadi, Madrid, 2003, p. 33.

39 En similar sentido, para Stein la averiguación de la verdad es un fin en algún sentido prioritario del proceso en materia de prueba, pero no es en absoluto el único. SteIn, A, Foundations of EvidenceLaw, citado en FerRer Beltrán, Jordi, "La prueba es libertad, pero no tanto: Una teoría de la prueba cuasibenthamiana", en ACCATINO, Daniela (Coord.), Formación y valoración de la prueba en el proceso penal, Ed. AbeledoPerrot, Santiago, 2010, p. 11.

${ }^{40}$ Obviamente no nos vamos a explayar respecto de este punto, pero es importante recordar que el Código Procesal Penal regula, a propósito de sus principios básicos, limitaciones constitucionales a la forma de investigar del Ministerio Público; a la legalidad de las medidas privativas o restrictivas de libertad; reconoce las facultades, derechos y garantías constitucionales al imputado desde la primera actuación en su contra; limita las privaciones de los derechos que la Constitución asegura a la autorización previa del juez y, por último, autoriza que se cautelen las garantías del imputado cuando éste no está en condiciones de ejercer los derechos que le reconoce la Constitución. Luego, en el derrotero del Código Procesal Penal existen otras normas, vinculadas a los derechos del imputado: la nulidad procesal y el recurso de nulidad, donde el Código hace una expresa referencia a la Constitución como límite del ejercicio del iuspuniendi. Respecto de la exclusión de prueba por haber sido obtenida con ilicitud, el Código utiliza una expresión aún más amplia, y por ende, con mayor extensión de aquello que está consagrado en la Constitución, señalando que se puede excluir prueba obtenida con inobservancia de garantías fundamentales, lo que repite en el Art. 334 a propósito de la prohibición de lectura de registros y documentos.

${ }^{41}$ En el mismo sentido, Alchourron, Carlos;Bulygin, Eugenio,Análisis lógico y Derecho, Centro de Estudios Constitucionales, Madrid, 1991, p. 312.
} 
En ese sentido, por ejemplo, el valor que tiene la presunción de inocencia, el derecho a guardar silencio y la carga de la prueba, permiten pensar, que en la ecuación (verdad v/s respeto a las garantías fundamentales) el sistema parecería optar por favorecer la posibilidad de una absolución errónea por sobre una condena errónea. Como se ha dicho históricamente" es preferible que diez culpables queden en libertad antes que un inocente preso" ${ }^{\prime \prime 2}$, con lo que se quiere decir, como es obvio, que es mejor optar por un sistema que privilegie la posibilidad de una absolución errónea antes que una condena injusta.

En definitiva, no se trata, creemos, de que el modelo acusatorio renuncie a la pretensión de búsqueda de verdad, epistemológicamente sigue existiendo un interés de alcanzar una verdad para poder adjudicar responsabilidad por un hecho típico al imputado, pero, de ahí no se deriva que aquélla deba ser buscada a toda costa, ni menos, que deba entenderse como una verdad material.

\section{INCORPORACIÓN DE LA DUDA RAZONABLE EN EL CÓDIGO PROCESAL PENAL ${ }^{43}$}

Cuando se envió el anteproyecto del Código Procesal Penal, su Art. 398 señalaba que nadie podía ser condenado sino cuando el tribunal hubiere adquirido la convicción de que se cometió un hecho punible y que en él le cabía participación culpable al acusado. Es decir, prácticamente no se presentaban mayores cambios con respecto a lo que disponía el Art. 456 bis del Código de Procedimiento Penal.

Más tarde, este Art. 398 pasó a ser el Art. 380 del proyecto de la Cámara de Diputados -ya estamos en 1998. Si bien se mantuvo el artículo en los términos recién descritos, se incorporó un nuevo inciso: la convicción debía formarse sobre la base de la prueba que se rinde en el juicio oral. Inciso que tenía su ori-

42 "Es preferible que diez culpables escapen, antes que un inocente sufra" fue la frase que uso el juez William Blackstone para justificar la presunción de inocencia. La ratio 10:1, que en Estados Unidos se conoce como la "Blackstone ratio", expresa la clásica idea americana de la presunción de inocencia y el estándar de convicción "más allá de toda duda razonable", pilares del sistema criminal. Volokн, Alexander, "Better than ten guilty men...", en KING, Larry (Ed.): Beyond a Reasonable Doubt, Ed. Phoenix, California, 2006, p. 87. En el mismo sentido, pero en la tradición continental, se refiere Verri cuando indica que "más vale perdonar a veinte culpables, que castigar a un inocente". VERRI, Pietro, "Observaciones sobre la tortura", citado por Carvalho, Salo de, Pena e Garantias: una leitura do garantismo de Luigi Ferrajoli no Brasil", Ed. Lumen Juris, Rio de Janeiro, p. 29.

43 Para mayor detalle, cfr., entre otros, Pfeffer Urquiaga, Emilio, Código Procesal Penal. Anotado y concordado., Editorial Jurídica de Chile, Santiago, 2001, pp. 340-341;Maturana MıQuel, Cristián (Coord.), Reforma Procesal Penal, Tomo II, Editorial Jurídica de Chile, Santiago, 2003, pp. 682-686; Urrutia Laubreaux, Daniel, "Aproximación al concepto de 'más allá de toda duda razonable", Boletín Centro de Estudios del Derecho,Universidad Católica del Norte № 2, 2002, pp. 2-3; Ríos Laulié, Francisco, "Estándar de convicción requerido para alcanzar una condena, propuesto en el nuevo Código Procesal Penal", en Seminario Reforma Procesal Penal, Universidad Católica de Temuco, 2001, pp. 247 y ss. 
gen en el Art. 261 del Código Procesal penal alemán ${ }^{44}$. Pues bien, este proyecto de la Cámara recibió la aprobación en general del Senado, el que procedió entonces a la discusión particular de las distintas disposiciones.

Es así que en junio de 2000, la Comisión de Constitución, Legislación, Justicia y Reglamento del Senado propuso algunas enmiendas al proyecto de la Cámara. Dentro de éstas se hallaba el Art. 380 en comento, el que pasó a ser el Art. 342. En lo que aquí interesa se estableció como estándar para condenar que el tribunal adquiriera suficiente convicción de que se ha cometido el delito y la participación del acusado en este hecho. Además, se agregó un inciso $3^{\circ}$ : nadie puede ser condenado con el solo mérito de su declaración. Principalmente, el cambio buscaba dejar claro que no era precisa una convicción absoluta o plena para condenar.

Dado que la Cámara desechó, entre otras, esta enmienda propuesta por el Senado al Art. 342, se constituyó en agosto de 2000 una Comisión mixta. Pues bien, es dentro de este contexto que surgió una tercera propuesta -las anteriores eran convicción y suficiente convicción-: convicción más allá de toda duda razonable. Es decir, se introdujo cuatro meses antes de que la reforma comenzara a funcionar en su primera etapa.

Si se revisan las actas legislativas no hubo mayor debate en torno a la incorporación de este nuevo concepto, salvo que se tuvo presente que se trata de un estándar de convicción propio del Derecho anglosajón y no del derecho europeo continental. Se destacó, además, que dicha medida de convicción resultaba útil, pues dejaba suficientemente claro que no era exigible una convicción absoluta para condenar, siendo suficiente que no se manifestaren dudas importantes.

Precisamente, en la Sesión 29 de la Cámara, de 17 de agosto de 2000, se afirma: "La Comisión Mixta tuvo presente que el estándar de convicción "más allá de toda duda razonable" es propio del derecho anglosajón, y no del europeo continental, por lo que resulta una novedad también para el ordenamiento jurídico chileno. Sin embargo, es un concepto útil, toda vez que está suficientemente decantado $o^{45}$ y elimina las discusiones relativas al grado de convicción que

\footnotetext{
${ }^{44}$ A modo casi anecdótico, podemos encontrar el primer atisbo (bastante inconsciente) de lo que sería el estándar de convicción finalmente aprobado, en la intervención del Diputado Elgueta durante la primera discusión en la Sala de la Cámara de Diputados del proyecto de Código, cuando indicó que "Asimismo, es fundamental en este proceso el respeto al principio de inocencia consagrado en los tratados internacionales, que se manifiesta en los siguientes aspectos: nadie está obligado a probar su inocencia y, en caso de duda, debe absolverse.". En todo caso, es pertinente resaltar la relación que el diputado hizo de la duda y la presunción de inocencia, pilar importante de la duda razonable, como se ha sostenido.

45 Llama la atención que Riego y Duce admitan que la motivación para la introducción del estándar de prueba del nuevo sistema procesal penal y, por lo mismo, de uno de los pilares donde descansa la etapa de adjudicación del juicio, lejos de provenir del estudio y razonamiento de las necesidades epistemológicas del proceso y su vinculación con las garantías, "provino de la experiencia práctica en el funcionamiento del juicio oral adquirida por algunos de los académicos que participamos en el proceso de reforma, en el contexto de programas de entrenamiento de destrezas de litigación y simu-
} 
"El estándar de convicción de la duda razonable en el proceso penal chileno, en particular la relevancia del voto disidente"

se requiere, dejando en evidencia que no se trata de una convicción absoluta, sino de aquella que excluya las dudas más importantes" ${ }^{\prime \prime 6}$.

\section{Exigencias de CONVICCIÓn EN El ANTIGUO SISTEMA PROCESAl PENAL}

Nos parece conveniente, para un mejor entendimiento del estándar en cuestión, exponer cuáles han sido los baremos exigidos en el antiguo sistema procesal penal. Ello, a fin de resolver si se aprecian divergencias y, de presentarse si éstas son insalvables o, por el contrario, se trata de una cuestión semántica, pero sin mayores repercusiones.

Como es sabido, el sistema inquisitivo ${ }^{47}$ comenzó a conformarse durante la Edad Media, con la decisiva influencia del derecho canónico, aunque históricamente ya en el Imperio Romano se empleaba, para ciertos delitos, un sistema similar, el que más tarde sería el inquisitivo ${ }^{48}$. Pues bien, se regulaban minuciosamente los medios a través de los cuales el juez debía adquirir su convicción, es decir, la existencia de una prueba cuyo valor se hallaba previamente determinado -prueba tasada-. Es así, por ejemplo, que el juez se encontraba totalmente vinculado a determinadas pruebas: los dichos de dos testigos eran suficientes para condenar ${ }^{49}$.

laciones de juicios que tuvieron lugar paralelamente a la discusión legislativa." DucE; RıEGo, Proceso Penal, cit. nota n. 3, p. 483. (lo destacado es nuestro).

${ }^{46}$ La cursiva no está en el original. ETCHEBerRY, "Consideración",cit. nota n. 25, pp. 671 y ss., crítica que se haya afirmado que se trata de un concepto decantado. Por el contrario, en el Derecho anglosajón a pesar del tiempo transcurrido, todavía se generan cuestionamientos. Cfr. Horvitz; López, Derecho Procesal, Tomo II, cit. nota n. 3, p. 158 y ss.

47 Para Ferrajol, Derecho y Razón, cit. nota n. 1, p. 564, lo que caracteriza al sistema inquisitivo es que el juez procede de oficio a la búsqueda, recolección y valoración de las pruebas, Ilegando al juicio después de una instrucción escrita y secreta de los que están excluidos o limitados los derechos de la defensa. Ilustrativo resulta lo expuesto por Foucault, Michel, Vigilar y castigar, Traducción de Garzón, Aureliano, Buenos Aires, Siglo XXI, 2002, pp. 41 y ss., para dar a conocer las particularidades del sistema inquisitivo entre los siglos XV y XVIII. El proceso era secreto hasta la sentencia, el que se desarrollaba sin el acusado o al menos sin conocer la acusación, los cargos, las declaraciones y las pruebas. El control absoluto lo tenía quien instruía el proceso. Asimismo, el acusado no tenía posibilidades de acceder a un abogado a fin de comprobar las irregularidades del proceso. La forma escrita y secreta del procedimiento respondía al principio de que en materia penal el establecimiento de la verdad era para el soberano y los jueces un derecho absoluto y un poder exclusivo. Ante la justicia del soberano, todas las voces deben callar.

${ }^{48}$ Cfr. Maier, Derecho procesal penal, cit. nota n. 29, pp. 284 ss.; FerRajol, Derecho y Razón, cit. nota n. 1, p. 565; Vázquez Rossı, Jorge,Derecho procesal penal, Tomo II,Rubinzal-Culzoni, Buenos Aires, 1997, p. 281;PaIlLAS, Enrique,Derecho procesal penal, Volumen I, Editorial Jurídica de Chile, Santiago, 1984, pp. 9 y ss.; FonteCilla Riquelme, Rafael,Tratado de Derecho procesal penal, $2^{\circ}$ Edición, Tomo I,Editorial Jurídica de Chile, Santiago, 1978, p. 39 y ss.

49 Como afirma Foucault, Vigilar, cit. nota n. 47, p. 42, para establecer la verdad debían aplicarse ciertas reglas. Precisamente el secreto imponía un modelo riguroso de demostración penal. Este autor destaca además, que este sistema de pruebas legales hacía que la verdad en la esfera penal fuera el 
Asimismo, la confesión del imputado adquiría extrema importancia en un orden -como se ha explicado- en el que la búsqueda de la verdad histórica ${ }^{50}$, principalmente en los orígenes del sistema inquisitivo, no sólo tenía como propósito la reconstrucción de hechos que se hallaban ocultos, porque así lo quería el autor-obviamente, no se reconocía la presunción de inocencia-, sino que además, se identificaba el delito con el pecado ${ }^{51}$. No sólo interesaba determinar la ocurrencia de un hecho, sino también el pensamiento, la intimidad del sujeto. Era el inquisidor quien poseía la verdad, por tanto, debía descorrer los velos que la ocultaban, pues si esto último ocurría era porque así lo quería el autor ${ }^{52}$.

Si bien la tortura comenzó a ser fuertemente cuestionada y derogada ya a mediados del siglo XVIII ${ }^{53}$-particularmente en Chile es abolida en la Constitución de $1828^{54}-$, no cabe negar que en nuestro sistema inquisitivo, en donde la confesión cumplía una función de especial preponderancia, todavía era posible encontrar determinados instrumentos dirigidos a interrogar al inculpado para lograr su confesión, y con ello conformar una prueba determinante -no hay

resultado de un arte complejo, que sólo era conocido por especialistas; cfr. BofILL, Jorge, "La prueba en el proceso penal", Revista de Derecho y Jurisprudencia T. XCI, N. 1, 1994, pp.21-22; PAILlas, Enrique, La prueba en el proceso penal, Editorial Jurídica de Chile, Santiago, 1982, pp. 12-13; RieGo, Cristián, "Nuevo estándar de convicción", Informe de Investigación de la Facultad de Derecho de la Universidad Diego Portales No 17, 2003, pp. 5-6.

${ }^{50}$ Cfr. Roxin, Claus, Derecho procesal penal, $25^{\circ}$ Edición Alemana, Traducción de Córdoba, Gabriela; Pastor, Daniel, Editores del Puerto, Buenos Aires, 2003, p. 558; Foucault, Vigilar, cit. nota n. 47, pp. 43-44; RIEGO, Cristián;DUCE, Mauricio, Introducción al nuevo sistema procesal penal, Universidad Diego Portales, Santiago, Volumen. 1, 2002, p. 51; RieGO, "Nuevo estándar", cit. nota n. 49, p. 6; PAILLAs, La prueba, cit. nota n. 49, pp. 77 y ss.

${ }^{51}$ FerRAJOLI, Derecho y Razón, cit. nota n. 1, p. 565, señala que la inquisición al reaparecer en el s. XIII con las Constituciones de Federico II tratándose de los procesos por crímenes de lesa majestad, respecto de los procesos eclesiásticos por los delitos de herejía y brujería, tales formas adquirieron mayor fuerza y dureza, pues el ofendido era Dios y por ello la acusación obligatoria y pública, suponía una investigación de la verdad que no admitía incertidumbre, por tanto la colaboración del acusado debía ser forzosa; Cfr. VázQuez, Derecho procesal, cit. nota n. 48, p. 289; Maler, Derecho procesal penal, cit. nota n. 29, p. 292.

52 En estos términos, VÁzquez, Derecho procesal, cit. nota n. 48, p. 291. Es por esta razón que la tortura adquirió tanta relevancia, pues era indispensable para lograr la confesión y así extraer la verdad. La tortura tuvo una minuciosa regulación -también como garantía para el imputado a fin de impedir actuaciones innecesarias- para así lograr que la confesión estuviera dotada de la necesaria calidad que permitiera reconstruir la verdad histórica. Cfr. MAIER, Derecho procesal penal, cit. nota n. 29, p. 293; Foucault, Vigilar, cit. nota n. 47, pp. 45 ss.; Palllas, Derecho procesal, cit. nota n. 48, pp. 38 ss.

53 Cfr. Foucault, Vigilar, cit. nota n. 47, p. 45; Paillas, Derecho procesal, cit. nota n. 48, pp. 54 ss.; PaILlas, La prueba, cit. nota n. 49, pp. 19 ss.; especialmente ilustrativo es lo expuesto por BeCCARIA, César, Tratado de los delitos y de las penas, Traducción deBernaldo De Quiros, Constancio,Editorial Cajicas, México, 1957, pp. 88 y ss.

${ }^{54}$ Art. 105: "Se prohíbe a todos los jueces, autoridades y Tribunales imponer la pena de confiscación de bienes, y la aplicación de toda clase de tormentos. La pena de infamia no pasará jamás de la persona del sentenciado." 
que olvidar que lo se busca es la verdad histórica y qué mejor que contar con la confesión del inculpado- ${ }^{55}$. Es así, que algunos medios del antiguo sistema procesal sí tenían la capacidad de mermar la voluntad del sujeto y con ello lograr la confesión ${ }^{56}$-empleo excesivo de la prisión preventiva, práctica habitual de la incomunicación, interrogatorios policiales sin mayores regulaciones (Art. 120 bis del Código de Procedimiento Penal), en fin, los sumarios prolongados- ${ }^{57}$. Por otro lado, dada la exigencia de la debida correlación entre el fallo y el grado de certeza, ello daba lugar a que mientras lo anterior no acontecía se sobreseía temporalmente la causa, manteniéndose sobre el sujeto la constante incertidumbre acerca de la reiniciación del proceso.

En este contexto se comprende el Art. 456 bis del Código de Procedimiento Penal, el que esencialmente exige que los jueces Ileguen a la certeza o seguridad de que se ha cometido el delito y la participación a través de los medios de prueba legal y en donde la confesión adquiere especial importancia ${ }^{58}$.

En todo caso y demostrando con ello la carencia de una adecuada sistematización en esta esfera, debe hacerse notar que si bien el antiguo sistema procesal se establece la prueba legal ${ }^{59}$, también es posible hallar diversas disposiciones que se apartan de lo anterior, sobre todo respecto a determinados delitos, estableciendo otros sistemas probatorios. En este orden, pueden citarse, por ejemplo, el derogado Art. 36 de la Ley 19.366 -tráfico ilícito de estupefacientes ${ }^{60}-$, y el Art. 59 de la Ley 11.625 -respecto de los delitos de hurto y robo ${ }^{61}-$.

\footnotetext{
${ }_{55} \mathrm{Al}$ respecto, cfr. Tortura, Derechos humanos y justicia criminal en Chile, Escuela de Derecho de la Universidad Diego Portales y Centro por la justicia y el Derecho Internacional, Santiago, 2002, pp. 34-36.

56 Así ya lo ha expuesto claramente, RieGo, "Nuevo estándar", cit. nota n. 49, pp. 8-9;RieGo; Duce, Introducción, cit. nota n. 50, pp. 343-346.

${ }^{57}$ Claramente se expone en Informe anual sobre Derechos Humanos en Chile en 200 (hechos de 2002), Facultad de Derecho de la Universidad Diego Portales, Santiago, 2003, p. 12-20, como el sistema inquisitivo no satisface siquiera la garantía más básica como es la del derecho a juicio.

58 Así, BofilL, "La prueba", cit., nota n. 49, p. 22. El juez no está obligado a someter su convicción al resultado de la prueba legal. Es decir, no sólo debe decidir sobre la base de dichas reglas, sino también sobre su convicción personal. Lo que el juez no puede hacer es adquirir la convicción por otros medios de prueba.

59 Para Abalos, Washington,Derecho procesal penal, Tomo II, Ediciones Jurídica de Cuyo, Santiago, 1993, p. 403, no es lo mismo hablar de prueba legal que prueba tasada o tarifada. En efecto, tratándose de la prueba tasada, la ley no sólo precisa los medios de prueba sino que además determina el valor de éstas. En cambio, respecto de la sana crítica racional o de íntima convicción es posible regular los medios de prueba -por tanto, existe también un sistema de prueba legal-, pero no se les asigna un determinado valor probatorio, dejándose que el juzgador libremente seleccione los medios que motivan su decisión.

60 Art. 36: "En la sustanciación y fallo de los procesos por los delitos a que se refiere esta ley, los tribunales apreciarán la prueba de acuerdo con las reglas de la sana crítica".

${ }^{61}$ Art. 59: "En los procesos por delitos de robo y hurto los Tribunales apreciarán la prueba en conciencia".
} 
Pues bien, desde el momento en que el nuevo Código Procesal Penal ha establecido otros criterios respecto a la prueba -Art. 295 y ss.-, muy diversos a los regulados en el antiguo sistema procesal penal, obliga a resolver cómo deben entenderse, a fin de que exista la debida coherencia con los nuevos estándares de prueba exigidos a los juzgadores. Esto es, por un lado la consagración de un sistema de libertad de medios de prueba, la aplicación de la sana crítica, y por otro la superación del umbral de la duda razonable.

\section{IV.I. Algunos apuntes históricos sobre la íntima convicción y la sana crítica, para desde ahí entender la duda razonable}

Para hacernos cargo de la interrogante precedente, nos referiremos brevemente a lo acontecido en la Europa continental y la estrecha vinculación que se presenta entre el sistema de libertad de prueba y el criterio de la íntima convicción, como regla del convencimiento del tribunal ${ }^{62}$.

A partir de la Revolución francesa comenzaron a apreciarse cambios que derivaron en la caída del sistema inquisitivo, propio del Antiguo Régimen ${ }^{63}$. Se apreciaba al sistema inglés de justicia como un modelo a seguir: la participación de legos a través del jurado y la libre apreciación de la prueba ${ }^{64}$. Es así que el Código de instrucción criminal francés de 1808 establecía la instrucción a los jurados, donde éstos debían llegar a la intime conviction sin que se requiriera mayor motivación ${ }^{65}$. Un fenómeno similar aconteció en otros países europeos, en los que el Código francés de 1808 sirvió de modelo. Es así, que en Alemania los jurados tampoco tenían la obligación de motivar sus decisiones. A pesar de las críticas que tal situación generaba, no fue sino hasta 1924, cuando en esta última nación se suprimieron los jurados -manteniéndose la libre valoración de la prueba-, y en donde los jueces comenzaron a fundamentar sus sentencias a fin de exponer cómo alcanzaban su convicción ${ }^{66}$.

\footnotetext{
${ }^{62}$ Cfr. el somero examen que hace Etcheberry, "Consideración", cit. nota n. 25, pp. 665 y ss.

${ }^{63}$ Para conocer la evolución experimentada en dicho período, MitTermaier, Kart Joseph, Tratado de la prueba en materia criminal, Traducción de González Del Alba, Primitivo, Hammurabi, Buenos Aires, 2006, pp. 45 ss.; Cfr. VeGas TorRes, Jaime, Presunción de inocencia y prueba en el proceso penal, La Ley, Madrid, 1993, p. 157; Roxin, Derecho, cit. nota n. 50, pp. 563 ss.;PallLas, La prueba, cit. nota n. 49 , p. 25 y ss.

${ }^{64}$ Cfr. Roxin, Derecho, cit. nota n. 50, p. 564.

${ }^{65}$ Cfr. BofILl, "La prueba", cit.nota n. 49, p. 22; MAIER, Derecho procesal penal, cit. nota n. 29, pp. 353 ss.;

${ }^{66}$ Cfr. BoflLL, "La prueba", cit. nota n. 49, p. 23; Roxin, Derecho, cit. nota n. 50, p. 565 y ss.; MuÑoz CONDE, La búsqueda, cit. nota n. 30, p. 116, para quien la intime conviction conduce a un subjetivismo extremo en el que en muchas ocasiones los "hechos probados" se convierten en una auténtica "caja de sorpresas".
} 
"El estándar de convicción de la duda razonable en el proceso penal chileno, en particular la relevancia del voto disidente"

En España, en cambio, la exigencia de motivación en cuanto a la valoración de la prueba tuvo como piedra angular una sentencia del Tribunal Constitucional de 28 de julio de $1981^{67}$. En efecto, hasta esa fecha los jueces apreciaban las pruebas de un modo libre, sin más limitación que sus propias facultades valorativas -libertad del juzgador en la formación de su convencimiento. Incluso, se admitían como material probatorio los antecedentes reunidos durante la investigación ${ }^{68}$. Tales criterios cambiaron radicalmente a partir de la sentencia mencionada, al señalar que independientemente de la convicción personal del juez, se requería para condenar que éste, sobre la base de la prueba rendida en el juicio, explicara por qué se debía desvirtuar la presunción de inocencia. Si bien el juzgador era libre en la apreciación de la prueba, era esencial una mínima actividad probatoria -con respeto a las garantías procesales- de la que se desprenda la culpabilidad del sujeto. El juzgador no podía prescindir de las pruebas practicadas en proceso y solamente sobre la base de éstas podía apoyar el juicio fáctico de la sentencia y conformar su convicción ${ }^{69}$.

Pues bien, esencialmente en el Derecho continental europeo se juzga a través de la prueba libremente apreciada, aunque con ciertas restricciones para su valoración, como son las máximas de la experiencia o el razonamiento lógico, las que el juez debe exponer en su fundamentación a fin de hacer posible el debido control ${ }^{70}$. Además, el juzgador alcanza determinadas conclusiones por una convicción personal, no requiriéndose, para determinar la culpabilidad del

\footnotetext{
${ }^{67}$ Con detalle, Vegas, Presunción de inocencia, cit. nota n. 63, pp. 164 y ss.

${ }^{68}$ Así, Vegas Torres, Presunción de inocencia, cit. nota n. 63, pp. 159 y ss., quien señala que el propio Tribunal Supremo sostenía la ilimitada libertad del juzgador en la averiguación de la verdad. El juzgador no se hallaba vinculado por las reglas de la sana crítica, ni a las de la lógica o la razón en su tarea de apreciación de la prueba.

${ }^{69}$ VeGAS, Presunción de inocencia, cit. nota n. 63, p. 167, cita la sentencia del Tribunal Supremo español -19 de febrero de 1988- que al referirse a la presunción de inocencia señala: "En el seno del proceso penal, la traducción de tan prestante y apreciada regla estriba ab initio inocente al inculpado, traspasando a las partes acusadoras la carga aportadora de aquellos elementos de prueba capaces de trocar ese planteamiento inicial en un fundado y razonable veredicto culpabilístico; y ello de tal modo que, ante un vacío de aportaciones, ante cualquier fracaso en el suministro de datos reveladores de la efectiva participación del encausado en el hecho criminal investigado, se impone su absolución con independencia de la convicción íntima subyacente en el ánimo del juzgador".

70 Como señala IgartúaSAlaverría, Juan, El caso Marey. Presunción de inocencia y votos particulares, Trotta, Madrid, 1999, pp. 13 ss. la motivación de las sentencias desempeña dos funciones, a saber, una burocrática -o técnico-jurídica- y otra democrática -o social-. Precisamente, esta función social de la motivación no se ve afectada por el hecho de que en la práctica muy pocos lean las sentencias, pues debe entenderse que la fundamentación no sólo legitima la decisión frente a la sociedad, sino también, lo que puede ser aún más importante: la legítima frente al justiciable. El condenado debe poder comprender las razones que invoca el Estado para privarle de uno o más de sus derechos fundamentales. Cfr., asimismo, Ferrajolı, Derecho y Razón, cit. nota n. 1, pp. 622-623.
} 
sujeto, una certeza absoluta. Basta que en su motivación el juzgador presente fundamentos plausibles que expliquen su convicción ${ }^{71}$.

Llegado a este punto, ya es posible arribar a una conclusión. El concepto de la íntima convicción, cuyo origen lo encontramos en la Revolución francesa y que se ha extendido por la Europa continental, surge esencialmente como oposición al sistema de la prueba tasada ${ }^{72}$. El Tribunal ya no está obligado a condenar por la sola circunstancia de que se hubieran reunido determinadas pruebas; asimismo, el tribunal tiene la libertad para condenar sobre la base de cualquier prueba rendida en juicio siempre que la encuentre determinante, motivando, claro está, su decisión. Empero, en esta esfera no se exigen niveles de certeza en cuanto a las pruebas para alcanzar la íntima convicción. El tribunal tiene plena libertad -respetando determinados principios que pongan de manifiesto un proceso lógico y racional- para decidir acerca de la preeminencia de una prueba sobre otra. En cambio, en el ámbito anglosajón sí se exigen niveles de prueba, los que han sido elaborados principalmente por la jurisprudencia -infra serán precisadas. Por de pronto, ello permitiría absolver penalmente y condenar civilmente, lo que para el derecho continental resulta bastante inusual.

El que nuestro antiguo sistema procesal hable de convicción se debe a que su comprensión se tomó de los sistemas europeos continentales. Por tanto, no difieren mayormente, independiente del sistema de prueba seguido o si se trata de un tribunal letrado, escabinado o de jurado. Es más, así puede leerse en el Mensaje del Código Procedimiento Penal en 1906: "Si esa convicción no llega a formarse, el juez podrá absolver sin otro fundamento y cualesquiera que sean los antecedentes que el proceso arroje en contra del reo"73. Así, Vera al comentar el Art. 484 del Código de Procedimiento Penal (hoy 456 bis) señalaba lo siguiente: "Lo que se establece por el artículo en estudio, es que se deja al juez de derecho cierta latitud para apreciar la prueba en cada caso i formarse una convicción sobre la inocencia o culpabilidad del procesado ya que no es posible sujetar a reglas fijas la prueba de los hechos criminales. Se puede decir que con el precepto referido, se ha calcado la lei de 3 de agosto de 1876 i se dá al juez en esta materia la amplitud propia de un jurado" ${ }^{\prime 74}$.

\footnotetext{
${ }^{71}$ El derecho a la tutela judicial efectiva supone la obtención de una resolución fundada en el derecho, lo que exige su motivación. Para conocer la jurisprudencia española sobre esta materia, cfr. Rodrícuez FERNÁNDEZ, Ricardo,Derechos fundamentales y garantías individuales en el proceso penal, Comares, Granada, 1999, pp. 4 y ss. Asimismo, Carocca Pérez, Alex, Garantía Constitucional de la Defensa Procesal, Bosch, Barcelona, 1998, pp. 340-342

72 EtCheberry, “Consideración", cit. nota n. 25, p. 669.

73 La cursiva no está en el original.

${ }^{74}$ Vera, Robustiano, Código de Procedimiento Penal. Comentado y concordado. Imprenta El Debate, Santiago, 1906, p. 408.
} 
De lo expuesto puede afirmarse que si nuestro Código Procesal Penal hubiera mantenido la regla de la convicción -como norma de convencimiento para el tribunal-, tal como tradicionalmente se ha comprendido, esta discusión no habría tenido lugar. Empero, como se ha querido innovar, y sin mayores explicaciones, resulta obligado buscar un sentido que, como se verá infra, a fin de evitar ciertas inconsistencias ${ }^{75}$.

\section{La duda Razonable en el sistema del Common LaW}

A pesar de que nuestro Parlamento afirmó que el concepto de la duda razonable se encontraba suficientemente decantado, ello no es así. Por el contrario, en el derecho anglosajón aún se presentan serias interrogantes en cuanto a su alcance $^{76}$. Es más, se ha debatido si resulta apropiada su definición cuando se debe instruir al jurado ${ }^{77}$. Sin perjuicio de los cuestionamientos que en este orden se presentan, en los casos en que sí se instruyen a los jurados en un proceso penal se les instruye, por ejemplo, de la siguiente manera: ${ }^{78}$

"Prueba más allá de toda duda razonable es aquella prueba que los deja firmemente convencidos de la culpabilidad del acusado. Hay pocas cosas en este mundo que nosotros conocemos con absoluta certeza, y en los casos criminales la ley no requiere pruebas que superen toda posible duda. Si basados en su consideración de la evidencia, ustedes están firmemente convencidos que el acusado es culpable de los cargos, deben hallarlo culpable. Si, por otro lado, ustedes creen que hay una posibilidad real de que no sea culpable, deben darle el beneficio de la duda y encontrarlo no culpable".

Como ya se señaló, aun cuando se trata de un concepto del que ya se pueden encontrar rastros en el s. XVIII, en los Estados Unidos su comprensión dentro de la garantía del debido proceso recién tuvo lugar en 1970, cuando la Corte Suprema federal, en el caso In Re Winship [397 US 358 (1970)], resolvió que

\footnotetext{
${ }^{75}$ Crítico también se muestra, ETCHeBerRY, "Consideración",cit. nota n. 25, pp. 671 y ss.

${ }^{76} \mathrm{Y}$ de hecho, no son pocos los autores y jueces que desde hace un tiempo han comenzado a criticar el estándar de duda razonable y a sugerir un incremento del estándar. Así, por ejemplo, se ha sugerido que la solución es adoptar la instrucción propuesta por la Federal Judicial Center, que describe la duda razonable como la exigencia de que el jurado esté "firmemente convencido" de la responsabilidad del imputado. Victor v. Nebraska, 511 U.S. 1, 26 (1994). En el mismosentidoSolan, Lawrence, "Refocusing the Burden of Proof in Criminal Cases: Some Doubt About Reasonable Doubt", Texas Law ReviewN. 78, 1999, pp.105, 144.

77 Park; Leonard; GoldberG, Evidence, cit. nota n. 21, p. 90.Al respecto, EtcheberRy, "Consideración",cit. nota n. 25, pp. 673 y ss., quien hace presente las dificultades que la precisión de la duda razonable genera en el mundo anglosajón.

${ }^{78}$ Cfr. En:http://www.lectlaw.com/files/cri09.htm[visitado el 03/05/2011].
} 
el ente acusador debía probar la culpabilidad del acusado más allá de toda duda razonable $e^{79}$.

Dicha sentencia señala: "Lest there remain any doubt about the constitutional stature of the reasonable-doubt standard, we explicitly hold that the Due Process Clause protects the accused against conviction except upon proof beyond a reasonable doubt of every fact necessary to constitute the crime with which he is charged ${ }^{\prime 80}$.

Sin pretender entrar en mayores disquisiciones, en general puede decirse que en el Derecho anglosajón la duda razonable se entiende, mayoritariamente, con un carácter fuertemente subjetivo, como estar frente una duda fundada sobre la base de la razón y el sentido común -incluso, se llega a hablar de la necesidad de certeza moral ${ }^{81}$ - y no sobre la base de puras especulaciones ${ }^{82}$. En consecuencia, la exigencia de la superación del umbral de la duda razonable dice relación con la obligación de quien tiene el peso de la prueba -burden of proof- de refutar la presunción de inocencia a través de pruebas que vayan más allá de toda duda razonable. Como afirma Chiesa Aponte, desde una perspectiva cualitativa del estándar probatorio: "La prueba más allá de toda duda razonable no significa certeza absoluta ni certeza matemática; es suficiente la convicción o certeza moral en un ánimo no prejuiciado" ${ }^{\prime \prime 3}$.

Al respecto, en la citada sentencia In Re Winship se afirma: "Moreover, use of the reasonable-doubt standard is indispensable to command the respect and confidence of the community in applications of the criminal law. It is critical that the moral force of the criminal law not be diluted by a standard of proof that leaves people in doubt whether innocent men are being condemned. It is also important in our free society that every individual going about his ordinary affairs have confidence that his government cannot adjudge him guilty of a criminal offense without convincing a proper factfinder of his guilt with utmost certainty".

Pues bien, ¿cuáles son los niveles de prueba que se han desarrollado en el mundo jurídico norteamericano? Es decir, cuáles son los estándares de prueba -Standars of Proof- que se disponen. Al respecto, es posible distinguir tres niveles, a saber, más allá de toda duda razonable, que es el más estricto y el

\footnotetext{
${ }^{79}$ Chiesa, Derecho procesal, Vol. II, cit. nota. 21, p. 51; LAfave, Wayne R.; ISRAEL, Jerold H.; KING, Nancy J.,Criminal Procedure, $3^{\circ}$ Edición, West Group, Saint Paul, MN, 2000, p. 540; Horvitz; López, Derecho Procesal, Tomo II, cit. nota n. 3,p. 154, traduciendo el dictum relevante de la sentencia en cuestión.

${ }^{80}$ En:http://caselaw.lp.findlaw.com/scripts/getcase.pl?court=US\&vol=397\&invol=358[visitado el 03/05/2011].

81 Sobre el punto, Horvitz; López, Derecho Procesal, Tomo II, cit. nota n. 3,p. 162-164;

${ }^{82}$ De hecho, la propia Corte Suprema de Estados Unidos ha reconocido, reiteradamente, que la duda razonable es un criterio subjetivo. Así, en el caso Jackson V. Virginia, el máximo tribunal estadounidense sostuvo que el jurado, para poder condenar a alguien, debía lograr "un estado subjetivo cercano a la certidumbre". Cfr. críticamente, LAUDAN, "Por qué un estándar de prueba subjetivo", cit. nota n. 9, p. 105.

${ }^{83}$ CHIESA, Derecho procesal, Vol. III, cit. nota n. 21, p. 378.
} 
"El estándar de convicción de la duda razonable en el proceso penal chileno, en particular la relevancia del voto disidente"

exigible para los casos criminales, a continuación está la prueba clara y convincente $^{84}$, y por último, la prueba preponderante ${ }^{85}$-para los casos civiles- ${ }^{86}$. En este sentido, Fletcher $^{87}$, a fin de graficar los niveles de exigencias recién descritos, recurre al siguiente ejemplo: si se está en un campo deportivo con líneas numeradas de 1 a 100, se supera el estándar de la duda razonable cuando el balón llega a la línea 9988; respecto a la prueba clara y convincente

\footnotetext{
${ }^{84}$ El estándar de prueba "clear and convincing" fue usado, por primera vez, por la Corte de Apelaciones de Nueva York cuando debió resolver un caso sobre el derecho a la muerte. El JuezWachtlerdefinió el estándarseñalandoque"Clear and convincing proof should... be requiered in cases where it is claimed that a person, now incompetent, left instructions to terminate life sustaining procedures when there is no hope of recovery". El mismo estándar fue luego utilizado por la Corte Suprema de los Estados Unidos, en el conocido caso sobre el derecho a la muerte Cruzan v. Director, Missouri Department of Health, 497 U.S. 261 (1990).

${ }^{85}$ También denominado, "preponderancia de las evidencias". En el sistema canadiense, este estándar se conoce como "balance of probabilities".
}

${ }^{86}$ Lafave; Israel; King, Criminal Procedure, cit. Nota n. 79, p. 540; Park; Leonard; GoldberG, Evidence, cit. nota n. 21, pp. 89-90; ChIESA, Derechoprocesal, Vol. III, cit. nota n. 21, p. 378; Dressler, Joshua;THOMAS III, George C.,Criminal Procedure: Principles, Policies and Perspectives, West Group, Saint Paul, MN, 1999, pp. 1246-1250; Horvitz;LópezMasle, DerechoProcesal, Tomo II, cit. nota n. 3, p. 155. Podríamos, citando a Gascón, definir el estándar de prueba preponderante como aquel en que una hipótesis sobre un hecho resultará aceptable o probada cuando sea más probable que cualquiera de las hipótesis alternativas sobre el mismo hecho manejadas o consideras en el proceso y siempre que dichas hipótesis resulte más probable que no; es decir, más probable que su correlativa hipótesis negativa. GAscón, "Sobre la posibilidad de formular", cit. nota n. 4, p. 130.

${ }^{87}$ FletCher, George P,Conceptos básicos de Derecho Pena, Traducción de Muñoz Conde, Francisco, Tirant lo Blanch, Valencia, 1997, pp. 36-37.

${ }^{88}$ Hay diversas maneras de aproximarse al fenómeno de la duda razonable y en el mundo anglosajón la cuestión no ha sido pacífica. Así, algunos autores, en general los académicos como Fletcher, prefieren una aproximación Bayesiana, eminentemente probabilística y profundamente subjetiva, al estándar de prueba. Y, entonces, suelen recurrir a un umbral de probabilidad (del 90\% al 95\%) que se debe lograr para poder condenar a una persona. Otros en cambio, han sugerido que los juicios son "historias" y el estándar de duda razonable sería -mirado cualitativa y también subjetivamente- la medida de la certeza que el jurado debería tener respecto de las narraciones de cada una de las partes, en especial del ente persecutor. Así, entonces, la duda razonable, quedaría reducida a carecer de toda duda, o tener una alta confianza subjetiva. Sin embargo, aplicar el modelo de la narración a los procesos penales ha sido problemático. Sobreéstocfr.Allen, Ronald, "A reconceptualization of Civil Trials", Buffalo University Law ReviewN. 66, p. 426 y ss; Allen, Ronald;Leiter, Brian: "Naturalized Epistemology and the Law of Evidence", VA Law ReviewN.87, 2001, p.1491, p. 1528. Una crítica al modelo probabilístico en, LaUdan, "Por qué un estándar de prueba subjetivo", cit. nota n. 9, pp. 105 y ss. Sin perjuicio de las profundas críticas que pueden hacerse a ambos modelos de interpretación del estándar probatorio, los dos comparten una alta exigencia probatoria para alcanzar una condena. En la lógica bayesiana, se sostiene un porcentaje alto de probabilidad y, desde la óptica subjetiva, un nivel alto de confianza. Por lo mismo, no compartimos la posición de Riego y Duce cuando, a pretexto de un sistema que durante la etapa de investigación respeta la autonomía y los derechos del individuo, proponen un estándar de prueba-además de subjetivo-, reducido. Duce; Riego, Proceso Penal, cit. nota n. 3, pp. 483 y ss. 
si llega a la línea 70; y por último, tratándose de la prueba preponderante si alcanza la línea $51^{89}$.

De conformidad a lo expuesto, los estándares exigidos son diferentes dependiendo de quien asuma la carga de la prueba. Como es comprensible, el nivel más alto lo tiene sólo el Ministerio Público. Como órgano persecutor es el llamado a superar el máximo estándar, pues debe refutar la presunción de inocencia. No así el defensor, éste incluso tiene una exigencia menor que la prueba preponderante ${ }^{90}$. Es decir, si el defensor es capaz de introducir en el juicio niveles de duda que imposibiliten alcanzar al fiscal la línea de 99, impedirá a éste superar el estándar exigido, es decir, no podrá ir más allá de toda duda razonable. Y es que, precisamente, se ha introducido en el juicio una duda razonable. Por tanto, no cabe más que desestimar las pretensiones del fiscal ${ }^{91}$.

A través de algunos ejemplos se es posible clarificar lo recién expuesto, y dar cuenta de qué podría suceder, por ejemplo, en Estados Unidos.

Primer caso: El Fiscal acusa por un delito de homicidio. El defensor puede introducir elementos de valoración, equivalentes al de la prueba preponderante, de que se actuó en legítima defensa. O, en su caso, elementos que permitan sostener que los niveles de racionalidad exigidos respecto a la creencia de los presupuestos fácticos de la causa de justificación, hagan posible afirmar la plausibilidad de un error.

Segundo caso: problema de imputación objetiva: los Ilamados cursos causales no verificables $-v$. gr. caso de la colza ${ }^{92}-$. Como se trata de una cuestión probabilística, basta con introducir antecedentes que hagan posible sostener que también concurren otros factores productores del daño y que no están comprendidos causalmente en el comportamiento del acusado. Si es así se está frente a una duda razonable, lo que impide sostener las imputaciones del Ministerio Público.

\footnotetext{
${ }^{89}$ Delmas-Marty, Mireille (Dir.), Procesos penales de Europa, Traducción de Morenilla Allard, Pablo, Eijus, Zaragoza, 2000, pp. 621-622.

90 En estos términos, FletCher, Conceptos básicos, cit. nota n. 87, p. 37.

91 Con todo, debe advertirse que a los jueces, en general, no les gusta esta aproximación bayesiana al concepto de duda razonable, porque aquello sería un reconocimiento explícito de la falibilidad del sistema y de la posibilidad de que éste cometa errores. En cambio, prefieren esconderse detrás de discursos como el de la verdad formal, la verdad del juicio o la verdad procesal, que, no cabe duda, encierran un fuerte contenido decisionista.

${ }_{92}$ Es un caso muy conocido que tuvo lugar en España, en que numerosas personas sufrieron lesiones graves y enfermedades, e incluso la muerte, por haber consumido aceite de colza desnaturalizado, mezclado y adulterado con otras sustancias que no se pudieron determinar. Sin embargo, otras personas que también consumieron el aceite no desarrollaron ningún síndrome tóxico. Con detalle, cfr. Paredes Castañón, José Manuel;Rodríguez Montañés, Teresa; El caso de la colza: responsabilidad penal por productos adulterados o defectuosos, Tirant lo Blanch, Valencia,1995, passim.
} 
Con todo, no debe olvidarse que en el sistema anglosajón la decisión adjudicativa descansa en un grupo de ciudadanos que, componiendo el jurado, deben decidir acerca de si el Estado sobrepasó las exigencias del estándar de duda razonable. Por lo tanto, se trata de un grupo de ciudadanos, carentes de formación profesional, jurídica, filosófica y epistemológica, que suelen decidir sobre sus propias inclinaciones subjetivas y, además, sin ninguna obligación de fundamentar. En otras palabras, se trata de un modelo de juicio en que la decisión se legitima por el escenario de adversarialidad en que se da el juicio y el carácter representativo que los ciudadanos le dan a la decisión que adoptan. Es, en palabras de Taruffo, un sistema donde la subjetividad de la decisión es intrínseca al rol y a la función que se atribuye al jurado, y donde esa función no se funda en la objetividad y en la racionalidad de las decisiones de los jurados, sino en una especie de "acto de fe". Su legitimidad, como parece obvio, no descansa en el valor epistemológico de sus decisiones, sino que en una legitimación político-social ${ }^{93-94}$.

Cualquiera sea la valoración que uno pueda hacer del modelo norteamericano de jurado, y su valor democrático, inclusivo y de participación ciudadana en el proceso de adjudicación (político-social), lo cierto es que el modelo adoptado en Chile ha descansado, desde siempre, sobre la idea de un juez profesionalizado, técnico, experto y no elegido democráticamente. Su legitimidad -y por lo mismo su autoridad- no viene dada por el hecho de haber estudiado derecho, haber entrado a la Academia Judicial o ser nombrado por decreto presidencial. Su legitimidad democrática, por el contrario, viene dada -entre otras cosas- por la motivación y justificación de sus decisiones que, como es obvio, no pueden quedar entregadas a su subjetivismo, sino que a un proceso racional, sujeto a la ley e intersubjetivamente contrastable. Y en materia penal esto es particularmente relevante, porque en esos casos el juez tiene la potestad para privar de su libertad -en ciertos casos para siempre- a otro ciudadano. En nuestro sistema, entonces, las fundamentaciones del estándar de prueba, vinculadas a decisiones subjetivistas o de probabilidades posteriores (bayesianas), simplemente, no tienen sentido.

Por ello, la discusión que actualmente pueda haber en Estados Unidos respecto de la unanimidad del jurado es enteramente inoponible a nuestra realidad. En aquel modelo, el valor epistemológico no está presente. En con-

\footnotetext{
${ }^{93}$ TARUfFo, "Tres observaciones", cit. nota n. 17, p. 121.

94 Por lo mismo, resultan sugerentes todas las críticas que Pizzi le asigna al sistema procesal penal estadounidense, y particularmente al juicio oral, cuando sostiene que se ha transformado en un juicio indiferente frente a la verdad. Cfr. portodos, PIzzI, William: Trials Without Truth, New York University Press, New York and London, 1999. Ello, a pesar de que la Corte Suprema de Estados Unidos, en el año 1966 había sostenido que el propósito básico del juicio oral es buscar la verdad. Cfr. Tehan v. U.S. 406, (1966).
} 
secuencia, el debate sobre la unanimidad o no de las condenas debe mirarse desde el prisma de las decisiones democráticas y su valor político social, pero no desde la epistemología. Así, entonces, se entiende que en los casos Johnson v Louisiana ${ }^{95}$ y Apodaca v. Oregon ${ }^{96}$, la Corte Suprema de Estados Unidos haya dicho que la exigencia de la unanimidad no se encuentra consagrada ni regulada en la sexta ni en la decimocuarta enmienda. Además, resulta interesante ver como la discusión que ha habido en Estados Unidos y, en otros países del Common Law con sistema de jurado, respecto de la unanimidad nada tiene que ver con cuestiones epistemológicas, sino más bien con exceso de hung juries (juicios que deben anularse porque el jurado no alcanza la unanimidad) ${ }^{97}$; por situaciones de soborno o de falta de ética del jurado ${ }^{98}$; por la lentitud en lograr las unanimidades ${ }^{99}$; o incluso por valores asignados a la democracia, como las votaciones por simple mayoría ${ }^{100}$, entre otros. Cualquier lector con conocimiento de nuestra cultura jurídica y de nuestro sistema procesal penal podrá observar que ninguno de estos aspectos resultan centrales en la discusión sobre la unanimidad o la mayoría en nuestras decisiones jurisdiccionales..

\section{INTERROGANTES QUE PLANTEA El CONCEPTO DE LA DUDA RAZONABLE. QUÉ SUCEDE CON EL VOTO DISIDENTE}

Pues bien, lo expuesto supra hace pensar que el estándar de la duda razonable también va dirigido a los intervinientes, particularmente al Fiscal y al defensor, en cuanto a precisar cuál es el estándar de prueba exigible. Es decir, si el Fiscal quiere afirmar los hechos expuestos en la acusación y por tanto, sostener que efectivamente se está frente a un hecho punible y que cabe una participación culpable al acusado, las pruebas aportadas deben superar la exigencia de la duda razonable, objetivamente, respecto de cada uno de los jueces que integra el Tribunal. Esa es una de las formas más relevantes de ser coherentes con la pretensión de verdad del proceso y de una adecuada distribución de errores. No debe olvidarse que en el sistema anglosajón, lo que interesa son las verdades consensuadas y que la decisión adoptada por el jurado no requiere de

\footnotetext{
${ }^{95}$ Johnson v. Louisiana, 406 U.S. 356 (1972).

${ }^{96}$ Apodaca v. Oregon, 406 U.S. 404 (1972).

97 Jury Unanimity in California: Should it Stay or Should it Go?

${ }_{98}$ Brief of Amicus Curiae The Federal Public Defender for the District Court Oregon In Support of Petitioner, presentadopara ante la Corte Suprema de los EstadosUnidos en el caso Alonso Herrera v. The State of Oregon.

${ }^{99}$ DrABSCH, Talina, Majority Jury Verdicts in Criminal Trial, NSW Parliamentary Library Research Service, 2005.

${ }^{100}$ Amar, Akhil Reed, "Reinventing Juries: Ten Suggested Reforms", U.C. Davis Law ReviewN. 1169, 1995, pp. 1189 ss.
} 
"El estándar de convicción de la duda razonable en el proceso penal chileno, en particular la relevancia del voto disidente"

motivación ${ }^{101}$. Por tanto, en un sistema como el nuestro -que claramente tiene un preferencia hacia la correspondencia-, en donde el tribunal debe fundamentar sus decisiones -Art. 342 del Código Procesal Penal-, se presentan dificultades para conciliar, por una lado la exigencia de superación de la duda razonable para condenar y por la otra, la presencia de un voto minoritario, que también fundadamente -inciso final del citado Art. 342- está por absolver.

Como se ha señalado, se establece como una barrera que debe superar el acusador en las pruebas que presenta. Se trata, pues, de un estándar que debe expresar en sí mismo una cantidad objetiva de prueba, un quantum de prueba exigible. En consecuencia, surge la duda de cómo las mismas pruebas pueden para unos superar el estándar y para otros presentarse una duda razonable ${ }^{102}$.

Si lo que se ha querido es establecer un estándar objetivo a través del cual se pueda medir el grado de plausibilidad en la fundamentación de la sentencia, a nuestro modo de ver, bastarían con las reglas dispuestas en el Art. 297 del Código Procesal Penal. En efecto, allí se establecen claramente los niveles de exigencia para la valoración de la prueba, los que deben ser expuestos en la motivación de la sentencia, incluso en el voto de minoría. Por lo mismo, el juez está obligado -respetando los límites impuestos en el Art. 297 del Código Procesal Penal- a "objetivar" su propia decisión sobre los hechos, indicando los criterios seguidos y argumentando las razones por las que ha considerado que un determinado hecho estaba probado o no probado ${ }^{103}$.

En la decisión del caso y como dijimos supra, el juez ya dispone -además de la duda razonable- de otros criterios orientadores, como son el principio in

101 Así también lo expone EtCheberRy, “Consideración”, cit. nota n. 25, p. 677.

102 Compartimos, en ese sentido, con Bayón cuando sostiene que para considerar satisfactorio un estándar de prueba cualquiera -y eso se aplica al nuestro- debiera reunir cuatro requisitos. En primer término, y como lo hemos dicho tantas veces, no debe tratarse de un estándar subjetivo, por lo mismo no puede referirse a estados mentales del juzgados -como su "pleno convencimiento" su "ausencia de duda" - porque aquello es francamente incompatible con la concepción racionalista de la prueba. En segundo término, debe estar formulado en forma tal que haga posible determinar a través de procedimientos intersubjetivamente controlamos cuándo ha quedado satisfecho y cuándo no. En tercer lugar, su formulación debe ser tal que de su aplicación correcta resulte exactamente la ratio entre falsos positivos y falsos negativos. Por último, de su aplicación debe resultar esa distribución del riesgo, pero precisamente en razón de la calidad de los elementos de prueba y de las cadenas de inferencias probatorias que es preciso llevar a cabo a partir de los mismos. Cfr. BAyón, "Epistemología, moral y prueba de los hechos", cit. nota n. 28, p. 7. Si eso es así, y si nuestro Código Procesal Penal pretende tener un estándar de prueba satisfactorio, entonces lo razonable es que habiendo un voto de minoría, que cumpla con las obligaciones constitucionales y legales de motivación racional, analítica y objetiva, aquello debería impedir, como efectivo mecanismo de distribución del error, que el imputado sea condenado.

103 TARufFo, "Tres observaciones", cit. nota n. 17, p. 121. 
dubio pro reo ${ }^{104}$ y la presunción de inocencia. Si se mantiene la incertidumbre en cuanto a que la norma penal no puede orientar al juzgador -así, no se satisfacen las exigencias del tipo- ya sea para condenar o absolver, el principio in dubio pro reo lo lleva necesariamente a absolver. En efecto, de mantenerse la incertidumbre -in dubio-no queda más que adoptar una decisión favorable-pro reo- ${ }^{105}$. Luego, lo anterior nos conduce a una certidumbre, a saber, la certeza de la absolución y con ello la inocencia del acusado. Esto es, la absolución establece como cierto un hecho inicial, cuál es, de que todo hombre es inocente.

En definitiva, mientras el principio in dubio pro reo parte de una duda, a la que se le brinda relevancia jurídica como presupuesto de absolución, con la presunción de inocencia, la duda ya es un imposible jurídico: la aplicación de la presunción de inocencia ya no se funda en una duda, sino en la certeza de la inocencia ${ }^{106}$.

Quisiéramos a continuación, hacernos cargo de una afirmación que hemos expuesto en diversos pasajes de este trabajo, y dice relación con la relevancia del voto disidente. $\mathrm{Si}$, como se ha dicho, cuando se habla de duda razonable se está exigiendo fundamentalmente un quantum objetivo de prueba exigible, ¿de qué manera puede aquello compatibilizarse con la presencia de un voto particular, esto es, de un juez que también encuentra una solución jurídicamente concreta al caso sometido a juicio? Estamos pues, frente a una controversia entre las posiciones de quienes están llamados a resolver el conflicto.

\footnotetext{
104 Acerca del principio in dubio pro reo, cfr. MaIER, Derecho procesal penal, cit. nota n. 29, pp. 494 ss.

105 Dicho de otra manera, el principio in dubio pro reo, le otorga a un imputado un cierto grado de duda respecto de la imputación en su contra (si fuera todo duda no se podría condenar a nadie). Por lo mismo, su relación con la duda razonable -y sobre todo entendiendo que ella es un estándar particularmente alto- de inclusión. La duda razonable, en el ámbito del juicio, incorpora el principio in dubio pro reo. Así, en palabras de Laudan, el imputado debería ser absuelto, incluso si pensamos que es probablemente culpable, a menos que el nivel de culpabilidad satisfaga un estándar de prueba muy exigente. Por lo mismo, no hay beneficio de la duda que sea de fundamentación libre, independiente del estándar de prueba. LAUDAN, "Por qué un estándar de prueba subjetivo", cit. nota n. 9, p. 112.

106 En sentido, Vegas Torres, Presunción de inocencia, cit. nota n. 63, pp. 208-209, afirma: “En estos casos, ante la insuficiencia de la norma sustantiva para orientar la decisión, es preciso que el ordenamiento suministre al juzgador un criterio que, o bien le permita sustituir la incertidumbre derivada de la prueba (o de la ausencia de ella) por una certidumbre de origen legal (o constitucional) sobre la cual poder decidir, aplicando o dejando de aplicar la norma penal o bien le indique directamente el sentido que ha de dar a la decisión en caso de incertidumbre. En este terreno nos encontramos ya con una primera diferencia entre la forma de actuar el in dubio pro reo y la presunción de inocencia como criterios de decisión en caso de incertidumbre. En efecto, el in dubio pro reo actúa como regla que orienta directamente la decisión en sentido absolutorio, cuando la culpabilidad del acusado es incierta. Su propia formulación vincula directamente la incertidumbre (in dubio) con la decisión favorable (pro reo). La presunción de inocencia, en cambio, determina el sentido de la decisión de manera indirecta o mediata, sustituyendo la incertidumbre por la certeza de la inocencia del acusado, lo que conduce a su absolución por no darse el supuesto del hecho de la norma penal". CHIESA, Derecho procesal, Vol. II, cit. nota n. 21, p. 52.
} 
Desde el momento que estamos frente a un voto disidente, es que no se ha compartido la misma valoración de las pruebas reunidas en el juicio ${ }^{107}$. Si la posición expresada por el voto particular también es verosímil y razonable, ello significa, ya sea que el fiscal no pudo probar los hechos de la acusación o que la tesis planteada por la defensa introdujo dudas que pueden ser calificadas de razonables. Es decir, si se trata de una duda razonada o, dicho en otros términos, justificada razonablemente, en cuanto a que ésta satisface las exigencias establecidas en el Art. 297 del Código Procesal Penal, significa que no es arbitraria. Por el contrario, sería una argumentación que no corroboraría la hipótesis acusatoria, que no le daría a la misma el grado de correspondencia entre la acusación y la prueba aportada al juicio; es decir, desde una perspectiva epistemológica, una decisión que no comparte la proposición fáctica del ente acusador.

Dicho de otra manera, para que un voto de minoría sea adecuadamente razonado y efectivamente motivado y, por lo mismo, suficiente para impedir la condena de un imputado (incluso existiendo dos jueces cuya decisión sea condenar) se requiere del cumplimiento de ciertos requisitos básicos que permitan sustentar que aquél satisface las exigencias legales. En primer término, se debe tratar de una motivación disidente que se haga cargo, individualmente, de cada uno de los medios de prueba presentados en el juicio oral que, a su juicio, desvirtúen la acusación o permiten generar una duda razonable. Además, se requiere que se dé cuenta en detalle de las razones globales que permiten desechar la tesis acusatoria. Y por último, para el evento que la defensa hubiese presentado prueba, explicitar cómo aquella efectivamente abrió aristas o capítulos - plausiblemente paralelos- que permitan explicar ciertos vacíos o dar cuenta de ciertas dudas en la acusación ${ }^{108}$.

Si, por ejemplo, la tesis de la defensa ha sido capaz de convencer a uno de los jueces que ésta ha sido plausible, ha sido capaz de introducir dudas razonables, que de conformidad al principio in dubio pro reo impediría condenar. Dicho en otros términos, si la postura de la defensa es plausible, razonable, quiere decir que la otra tesis, la del fiscal, no ha podido superar el estándar exigido y, en consecuencia, su prueba no va más allá de la duda razonable. Las hipótesis de falsación de la defensa han sido suficientes para rebajar los niveles de prueba, impidiendo llegar a la máxima exigencia para poder condenar.

107 Sobre la importancia que puede tener el voto particular en una sentencia penal, cfr. IGARTÚA, El caso Marey, cit. nota n. 70, p. 28 y ss.; ETCHeBerRY, "Consideración", cit. nota n. 25, pp. 677-678.

108 Habiendo dicho esto, entonces, parece evidente que no compartimos en lo absoluto la así llamada "tesis Juicia" según la cual las sentencias absolutorias permitirían un nivel de argumentación inferior a las condenatorias, porque estas últimas -en razón de una garantía- requerirían mayor nivel de fundamentación. Esa tesis descansa -ahora desde la mirada de las sentencias absolutorias- en una perspectiva subjetivista de la duda razonable que se debe rechazar. 
En definitiva, si la postura minoritaria en su fundamentación, conforme a las exigencias del Art. 297 del Código Procesal Penal, estima, por ejemplo, que la tesis de la defensa estaba correctamente razonada, no es posible sino concluir que ésta era plausible. El fiscal fue incapaz de superar el umbral exigido para demostrar la comisión del hecho punible objeto de la acusación o la participación del acusado.

Es por lo expuesto supra que, a nuestro modo de ver, las sentencias condenatorias en materia penal deberían contar con la unanimidad de los votos ${ }^{109}$. Es más, podría pensarse que una sentencia condenatoria que contenga un voto disidente, en donde se expresa que existen dudas razonables acerca del hecho punible objeto de la acusación o de la participación culpable del acusado podría estar violentando el principio de presunción de inocencia ${ }^{110}$. En efecto, existiendo una incertidumbre "plausible", visos de razonabilidad sobre los puntos en cuestión, es que no se ha alcanzado el umbral que la propia ley establece para que el tribunal pueda condenar, a saber, ir más allá de la duda razonable.

Se puede argumentar que existen normas en el Código Orgánico de Tribunales -Art. 19- que se refieren a las decisiones de los Tribunales orales en lo

109 No desconocemos que la exigencia de unanimidad, incluso en sistemas que tienen un mecanismo de adjudicación por jurados está en retirada. Así, salvo Canadá, no hay otro país en el mundo que exija unanimidad para todos los juicios penales. En Estados Unidos, como se sabe, a nivel federal la exigencia es la unanimidad del jurado para condenar, pero no pasa lo mismo en los Estados de Louisiana y Oregon, que ahora permiten, incluso mediante reformas a sus constituciones estatales, la posibilidad de condenar con algo menos que la unanimidad. Sobre la discusión respecto de la unanimidad en el modelo norteamericano Cfr. DiAmond, Shari; Rose, Mary;MurphrBeth, "RevisitingtheUnanimityRequirement: TheBehavior of the Non-Unanimous Civil Jury", NorthwesternUniversityLawReview Vol. 100, N. 1, pp. 201 ss. En Inglaterra, por su parte, en el año 1967 se abolió la exigencia de la unanimidad, básicamente a consecuencia de una serie de casos de persecución a miembros de la mafia (London Gangsters) donde se alegó la existencia de sobornos y amenazas al jurado. Nada de eso se pudo comprobar. Cfr. Criminal JusticeAct 1967. En todo caso la exigencia o no de unanimidad en sistemas de jurado es irrelevante para nuestra discusión, porque a decir de Laudan, en esos modelos -aunque él pretende, a nuestro juicio erradamente, ampliarlo a otros modelos- existe un exceso de subjetivismo, el jurado no debe motivar sus decisiones $y$, probablemente, su razonamiento funciona más sobre la base de una pugna de historias, más que el análisis razonado de cada una de las pruebas presentadas en el juicio.Cfr. Laudan, "Por qué un estándar de prueba subjetivo", cit. nota n. 9, pp. 98 ss.

110 En el mismo sentido BÁEZ para quien la "decisión de condenada debe ser tomada por todos los miembros del órgano jurisdiccional colegiado, por tratarse de una operación jurídica de primer grado, por lo que en el evento de que uno de ellos no haya alcanzado esta certeza necesaria, existiendo a su juicio fundamentos razonables basados en los medios de prueba rendidos para no dar por acreditados las proposiciones fácticas relativas a la existencia del hecho punible o a la participación del acusado en él, el resultado del juicio debe necesariamente ser un veredicto de naturaleza absolutoria". El autor también comparte con nosotros la tésis que las decisiones en torno a cuestiones de carácter jurídico. calificantes puedan ser tomadas por simple mayoría. Lo que nos separa, en todo caso, es que él considera que se requiere una modificación legal para normativizarlo, nosotros consideramos que sí es posible, conforme a una interpretación constitucionalmente. Cfr., BáEz, “¿Estándar de convicción o arbitrariedad judicial?", cit. nota n. 5, p. 874. 
"El estándar de convicción de la duda razonable en el proceso penal chileno, en particular la relevancia del voto disidente"

penal y que permiten adoptar resoluciones por la mayoría absoluta -Art. $72{ }^{111}$. Por tanto, lo expuesto sólo podría tener valor como propuesta de lege ferenda siendo necesario adecuar nuestra normativa a la exigencia de unanimidad, si se pretende que exista la debida coherencia con este nuevo estándar de prueba.

Para responder lo anterior, creemos que es necesario efectuar ciertas distinciones. Cuando se está frente a hechos, el tribunal debe resolver por unanimidad, por exigencia del propio Art. 340 del Código Procesal Penal. Y es que la imposición de la superación de la duda razonable, dispuesta por la propia ley, supone que el tribunal en su conjunto considera que las pruebas producidas durante el juicio oral no presentan dudas razonables-conforme a los principios de la lógica, de las máximas de la experiencia y los conocimientos científicamente afianzados-, acerca de la existencia de un hecho punible y de la culpabilidad del acusado. Resulta del todo incoherente desde la perspectiva procesal, y contrario a la presunción de inocencia como se ha señalado supra, condenar cuando uno de los miembros del tribunal valora razonadamente que las mismas pruebas no son suficientes para alcanzar la exigencia de convicción.

Por lo anterior, somos del parecer que no es necesaria una reforma, pues de lege lata, atendido lo dispuesto en el Art. 340, se puede desprender la exigencia de la unanimidad para condenar, dado que la propia ley establece el estándar y sobre qué debe recaer la convicción del tribunal ${ }^{112}$.

En efecto, consideramos que una interpretación constitucionalmente correcta debiera considerar que una condena a un ciudadano, respecto del cual uno de los jueces del proceso adjudicatario estuvo por absolverlo mediante un voto efectivamente razonado, es inadecuada desde el derecho al debido proceso que, entre otras cosas, debiera considerar el estándar de prueba de duda razonable como una exigencia de unanimidad.

En cambio, si se está frente a consideraciones de derecho o cuestiones de carácter jurídico-calificantes; es decir, cuando no se presentan cuestionamientos en torno a la existencia del hecho punible y las discrepancias dicen relación con la figura típica que se conforma -siempre, claro está, que se ha llamado a

\footnotetext{
111 Art. 72. "Las Cortes de Apelaciones deberán funcionar, para conocer y decidir los asuntos que les estén encomendados, con un número de miembros que no sea inferior al mínimum determinado en cada caso por la ley, y sus resoluciones se adoptarán por mayoría absoluta de votos conformes."

112 Se podría criticar que esta postura generaría fuertes discrepancias para determinar en el Tribunal si el voto de minoría es razonado y motivado suficientemente, lo que podría generar confusiones para determinar cuándo procede o no la condena. La solución es bastante más sencilla, en esos casos el sistema recursivo operaría como debería hacerlo, es decir, si el Ministerio Público -o el querellanteconsideraran que el voto de minoría no cumple los requisitos del Art. 342, podría recurrir e intentar un nuevo juicio. Aquello, por cierto, en la lógica -que nosotros no compartimos- de que el Ministerio Público debiera tener derecho al recurso. Pero esta es una discusión de legeferenda hoy en nuestro sistema donde, por el contrario, hay texto expreso que reconoce el carácter de agraviado del Ministerio Público y por lo mismo legitimado para recurrir.
} 
recalificar- o la discusión guarda relación con el grado de participación culpable del acusado, sí cabe el voto minoritario. Por tanto, corresponde aplicar las reglas del Código Orgánico de Tribunales.

Cualquiera sea el resultado de esa discusión, creemos firmemente que en nuestro sistema debe abordarse el juicio de hecho desde una concepción cognoscitivista, esto es, estableciendo que la verdad en el proceso penal debe entenderse como correspondencia con la realidad ${ }^{113}$. Para ello, el tribunal tiene la obligación de valorar la prueba de manera analítica, crítica y racionalmente a la luz de las reglas de la lógica, las máximas de la experiencia y los conocimientos científicamente afianzados, sopesando las diversas alternativas que explican los hechos, y posteriormente, elegir aquella que con mayor probabilidad "inductiva" explican la ocurrencia o no de los datos fácticos ${ }^{114}$.

Por lo mismo, si en la sentencia uno de los jueces que integró el tribunal, después de haber hecho un adecuado razonamiento probatorio de naturaleza inductiva con cada una de las pruebas, comparando el grado de soporte inductivo con que cuenta cada hipótesis sobre los hechos a la luz de un conjunto dado de elementos de prueba, a saber, a través de la inducción eliminativa o de contrastación o corroboración de hipótesis ("probabilidad inductiva" o "baco-

113 Esto nos aleja, por cierto, de las concepciones más cercanas a la idea de verdad consensuada o de mera narración y nos acerca -como lo hemos hecho en el trabajo- a una relación más epistemológica del proceso penal. Y nos parece que no solamente hay razones teóricas, lógicas y políticas que permiten afirmar que esta postura debe prevalecer en nuestro modelo, sino que también razones de carácter positivas. Así, en nuestra normativa adjudicativa hay suficientes ejemplo que nos permiten sostener eso, a saber, y a modo simplemente demostrativo: la norma que autoriza al juez de garantía a reabrir la investigación y ordenar al Ministerio Público la realización de ciertas diligencias previamente solicitadas por las partes, a menos que fueran manifiestamente impertinentes, que tuvieren por objeto acreditar hechos públicos y notorios o que fueran puramente dilatorias (con lo cual el juez debe hacer un control de mérito - de correspondencia epistemológica de las mismas- para determinar su realización) -Art. 257-; o la que permite a las partes llegar a ciertas convenciones probatorias que, en todo caso, nos son completamente vinculantes para los miembros del Tribunal, si en el juicio oral se les presenta prueba contradictoria con aquella (con la debida motivación de su rechazo y las justificaciones de su refutación) -Art. 275-; aquella que permite a los jueces hacer preguntas aclaratorias en la declaración de imputados y testigos (que lo diferencia con la total pasividad, por ejemplo, que deben tener los miembros de un jurado) -Art. 326 y 329-; y la que permite que el tribunal -autónomamente- pueda constituirse en un lugar distinto de la sala de audiencias para apreciar determinadas circunstancias relevantes del caso -Art. 337-. Pero también existen otras normas que indudablemente permiten rechazar una posición favorable de nuestro proceso penal a las lógicas narrativas, como aquella que autoriza al Juez de Garantía a rechazar de oficio un principio de oportunidad -Art. 170-; la que permite que el juez de oficio niegue la aprobación de un acuerdo reparatorio cuando considerare que existe un interés público prevalente -Art. 241-; y las que facultan al juez para oponerse a un procedimiento abreviado o, incluso, dictar una sentencia absolutoria.

114 Entendemos -siguiendo a Accatino- que aquel voto de minoría debe satisfacer los estándares de fundamentación de la motivación y que, por lo mismo, se debe estructurar en forma dialógica y comprenda no sólo la justificación lineal de la hipótesis fáctica acogida, sino también la valoración singularizada de las pruebas desestimadas y la confrontación de las hipótesis desechadas. Cfr. AcCATinO, "La fundamentación de la declaración de hechos", cit. nota n. 5, p. 14. 
niana") Ilega a la conclusión que, o bien no se dio por probada la existencia del delito o la participación en él del imputado, entonces no se entiende cómo, a partir del voto de mayoría, esa descripción epistemológica de los hechos pueda "dejar de tener sentido" para el proceso penal, ser "irrelevante" y por lo mismo, no impedir la condena.

Corolario de la anterior, creemos que hoy se ha desvirtuado absolutamente el sentido y el alcance del recurso de nulidad, en lo que dice relación con el voto disidente ${ }^{115}$. En general, cuando existe un voto disidente la parte que se considera agraviada, que en general coincide con el voto de minoría, impugna la decisión sosteniendo que el razonamiento del voto de mayoría no cumplió con los requisitos del Art. 342 letra c) del Código Procesal Penal y, en cambio, que sí lo habría hecho el voto de minoría. De manera más o menos inconsciente, muchas veces lo que se pretende es que la Corte comparta la aproximación epistemológica (del razonamiento inductivo) del voto de minoría, dando a entender que aquel se acerca más a la verdad, a fin de que se anule el juicio o se dicte una sentencia más favorable para el imputado. Sostenemos que aquello no tiene mayor sentido, por cuanto en la distribución del error parece ser una inadecuada decisión política-moral. En cambio, como hemos dicho insistentemente, lo que debería ocurrir es que habiendo un voto de minoría -adecuadamente motivado y objetivamente razonado- aquel debería impedir la condena y, sólo en ese caso, el Ministerio Público (o el querellante) deberían poder recurrir para impugnar ese voto. Por ejemplo, porque se valoró los medios de prueba infringiendo los límites de la valoración de la prueba fijados en el Art. 297 del Código Procesal Penal.

\section{CONCLUSIÓN}

Se hace necesario iniciar una discusión sobre esta materia, pues hasta la fecha no se han extraído muchas de las consecuencias que se debieran derivar de este nuevo estándar de prueba. Como ya se señaló, en el debate legislativo no se reflexionó con la debida atención acerca de sus alcances y, por tanto, su posterior inclusión en el sistema procesal penal resulta del todo discutible. Sin perjuicio de ello, creemos haber demostrado que al entender el nuevo es-

115 No podremos abordar, por exceder el sentido del presente trabajo, dos aspectos centrales y polémicos de la regulación de nuestro recurso de nulidad en el proceso penal. Por un parte, lo restrictivo en cuanto a la posibilidad de poder revisar cuestiones de hecho en la impugnación de la sentencia de juicio oral y, en segundo lugar, la posibilidad del Ministerio Publico de poder asumir el rol de sujeto activo en el recurso e impugnar una sentencia de juicio oral, con el riesgo que ello conlleva de una segunda oportunidad en que el imputado sea condenado (Doublejeopardy). Trabajaremos, por ende, con la regulación actual de nuestro Código que, como se sabe, es absolutamente restrictivo en cuanto a la revisión de los hechos y que, además, no ve inconvenientes en que el Ministerio Público pueda impugnar decisiones de los tribunales orales en lo penal. 
tándar probatorio, que ha sido establecido en nuestro proceso penal, como un estándar de carácter objetivo debe, necesariamente, concluirse la absolución del imputado si uno de sus miembros -mediante un voto razonado y motivado conforme las normas legales- concluye que existe duda razonable. Como se ha expuesto a lo largo de este trabajo, la cuestión no es de orden cuantitativo, sino más bien, cualitativo. No parece razonable pensar que si dos integrantes han concluido que se cumplió con el estándar probatorio de condena, sólo ellos sí pudieron alcanzar un cierto grado de verdad, no así el disidente.

El estándar de prueba del proceso penal chileno es, como se ha dicho, particularmente alto, por cuanto exige que el tribunal adquiera la convicción "más allá de toda duda razonable" de la existencia del delito y la participación del culpable. Que ello sea así se justifica en cuanto mecanismo de distribución de errores, de forma tal que favorezcan sistemáticamente la posición del imputado. Por lo anterior, parece ilógico que la forma más idónea de controlar dicha distribución, la del voto de un juez disidente, no sirva para ello. Aquello, creemos, afecta claramente a la garantía del debido proceso.

Quienes consideran lo contrario, a nuestro juicio, confundirían el juicio oral con un escenario de debate de historias, quien tiene un "relato" mejor preparado, que logra convencer al juez -subjetivamente- de su teoría del caso ${ }^{116}$. En fin, que por presentar una historia más creíble, va a tener menos cabos sueltos o ser más lógica, siempre mirada como un todo y no como un análisis particular y analítico de cada prueba que vaya encaminado a buscar una verdad ${ }^{117}$. Entendiéndolo así, los jueces, por su parte, deberían conformarse con analizar el proceso penal como un todo y, bajo ese prisma, analizar si se ha cumplido con el estándar de duda razonable. A nuestro modo de ver, aquello es un error, pues el juez no está más que recurriendo a baremos puramente subjetivistas, considerando el juicio holísticamente, al dar su veredicto. En este contexto, por cierto, es comprensible que un voto de minoría no sea más que eso, "una minoría", lo cual es consistente con esta forma de comprensión del estándar de prueba, la que parece tener poco que ver con la búsqueda de la verdad.

\footnotetext{
116 Como afirma Accatino, en nuestra doctrina y en la práctica judicial sigue vigente -y no diríamos soterradamente- una noción subjetivista de la prueba, que entiende que el objetivo fundamental de la actividad probatoria es la de lograr la convicción del tribunal y que vincula conceptualmente la prueba de un hecho con la adquisición por parte del tribunal del estado mental consistente en la creencia en la ocurrencia de los hechos. Cfr. AcCATino, "La fundamentación de la declaración de hechos", cit. nota n. 5, p. 13.

117 Así, para Accatino, citando una abundante bibliografía, un modelo de justificación analítico es aquel que requiere una exposición pormenorizada de todas las pruebas practicadas, del valor probatorio que se les ha asignado y las razones que lo sustentan y de la cadena de inferencias que permite tener por justificadas las conclusiones probatorias. Cfr. ACCATINO, "La fundamentación de la declaración de hechos", cit. nota n. 5, p. 13.
} 
Debemos dejar de pensar en el juicio oral sólo como un escenario de sofisticadas $-y$ a veces innecesarias- reglas de admisibilidad y evidencia y debemos comenzar a verlo y tratarlo como un escenario en que lo fundamental es la búsqueda de la verdad y de la justicia.

\section{BibLIOGRAFÍA}

Abalos, Washington, Derecho procesal penal, Tomo II, Ediciones Jurídica de Cuyo, Santiago, 1993.

Accatino SCAGliottı, Daniela, "El modelo legal de justificación de los enunciados probatorios en las sentencias penales y su control a través del recurso de nulidad", en AcCatino SCAglototı, Daniela (Coord.), Formación y valoración de la prueba en el proceso penal, Ed. Abeledo Perrot, Santiago, 2010. "La fundamentación de la declaración de hechos probados en el nuevo proceso penal. Un diagnóstico", Revista de Derecho de la Universidad Austral de Chile, Vol. XIX, № 2, 2006.

Alchourron, Carlos; Bulygin, Eugenio, Análisis lógico y Derecho, Centro de Estudios Constitucionales, Madrid, 1991.

AlleN, Ronald; LeITER, Brian, "Naturalized Epistemology and the Law of Evidence", VA Law Review Nº 87, 2001.

AlLEN, Ronald, "A reconceptualization of Civil Trials", Buffalo University Law Review, № 66.

Amar, Akhil Reed, "Reinventing Juries, Ten Suggested Reforms", U.C. Davis Law Review No 1169, 1995.

AtIENZA, Manuel, Las Razones del Derecho, teorías de la argumentación jurídica, Universidad Nacional Autónoma de México, México D.F., 2005.

BÁEZ, Danilo, "¿Estándar de convicción o arbitrariedad judicial? Bases y propuestas para la interpretación del estándar de 'duda razonable' en el Código Procesal Penal", Verdugo M., Mario (Dir.), Gaceta Jurídica, Doctrinas Esenciales, Derecho Penal, Tomo 1, Legal Publishing Chile, Santiago, 2011.

BAYÓN, Juan Carlos, "Epistemología, moral y prueba de los hechos, hacia un enfoque no benthamiano". En: http,//www.udg.edu/LinkClick.aspx?file ticket=fYVRM58p9Z4\%3D\&tabid=9724\&language=en-US[visitado el 03/06/2011].

Beattie, John, Crime and the Courts in England 1660 - 1800, citado en LangBein, The origins of adversary criminal trial, Oxford University Press, Oxford, 2005.

BeCCARIA, César, Tratado de los delitos y de las penas, Traducción de Bernaldo De Quiros, Constancio, Editorial Cajicas, México, 1957. 
Blanco SuÁrez, Rafael, y Otros, Litigación estratégica en el nuevo proceso penal, Ed. LexisNexis, Santiago, 2005.

Bofill, Jorge, "La prueba en el proceso penal", Revista de Derecho y Jurisprudencia, T. XCI, N 1, 1994.

Boletín Centro de Estudios del Derecho, Universidad Católica del Norte, sede Coquimbo, No 4, 2003.

Carocca, Alex, y Otros, Nuevo proceso penal, Ed. Conosur Ltda., Santiago, 2000.

Carocca Pérez, Alex, Garantía Constitucional de la Defensa Procesal, Bosch, Barcelona, 1998.

ChIESA APOnte, Ernesto, Derecho procesal penal de Puerto Rico y Estados Unidos, Vol. II, Editorial Forum, Bogotá, 1995.

Coloma Correa, Rodrigo, "Panorama General de la Prueba en el Juicio Oral", en Coloma Correa, Rodrigo (Ed.), La Prueba en el Nuevo Proceso Penal Oral, Ed. LexisNexis, Santiago, 2003.

De Urbano, Eduardo; Torres, Miguel Angel, La Prueba llícita Penal, Ed. Thomson Aranzadi, Madrid, 2003.

Delmas-Marty, Mireille (Dir.), Procesos penales de Europa, Traducción de Morenilla Allard, Pablo, Eijus, Zaragoza, 2000.

Diamond, Shari; Rose, Mary; Murphy Beth, "Revisiting the Unanimity Requirement, The Behavior of the Non-Unanimous Civil Jury", Northwestern University Law Review, Vol. 100, № 1.

DrABSCH, Talina, Majority Jury Verdicts in Criminal Trial, NSW Parliamentary Library Research Service, 2005.

Dressler, Joshua; Thomas III, George C., Criminal Procedure, Principles, Policies and Perspectives. West Group, Saint Paul, MN, 1999.

DrESSLER, Joshua, Understanding Criminal Procedure, LexisNexis.

Duce, Mauricio; Baytelman, Andrés, Litigación penal en juicios orales, 2 ${ }^{\text {a }}$ Edición, Facultad de Ciencias Jurídicas y Sociales, Universidad Diego Portales, Santiago, 2002.

Duce, Mauricio; Riego, Cristián, Proceso Penal, Ed. Jurídica, Santiago, 2007.

EtcheberRy, Alfredo, "Consideración sobre el criterio de condena en el Código Procesal Penal", en Delito, pena y proceso. Libro Homenaje a la memoria de Tito Solari Peralta, Editorial Jurídica de Chile, Santiago, 2008.

FerRajol, Luigi, Derecho y razón. Teoría del garantismo penal, Traducción de Andrés Ibáñez, Perfecto et al., Ed. Trotta, Madrid, 1995.

FerRajol, Luigi, "Notas Críticas y Autocríticas en Torno a la Discusión Sobre Derecho y Razón", Traducción de Guzmán, Nicolás, Revista de Ciencias Jurídicas Más Derecho 2001/II. 
Ferrer Beltrán, Jordi, "La prueba es libertad, pero no tanto. Una teoría de la prueba cuasi-benthamiana", en ACCATINO, Daniela (Coord), Formación y valoración de la prueba en el proceso penal, Ed. Abeledo Perrot, Santiago, 2010.

Ferrer Beltrán, Jordi, Prueba y verdad en el derecho, $2^{\text {a }}$ Edición, Marcial Pons, Madrid, 2005.

FletCher, George P., Conceptos básicos de Derecho Penal, Traducción de Muñoz Conde, Francisco, Tirant lo Blanch, Valencia, 1997.

Fontecilla Riquelme, Rafael, Tratado de Derecho procesal penal, 2ª Edición, Editorial Jurídica de Chile, Santiago, Tomo I, 1978.

Foucault, Michel, Vigilar y castigar, Traducción de Garzón, Aureliano, Buenos Aires, Siglo XXI, 2002.

Gascón AbelLÁN, Marina, "Sobre la posibilidad de formular estándares de prueba objetivos", DOXA, Cuadernos de Filosofía del Derecho № 28, 2005.

Gascón Abellán, Marina, Los hechos en el derecho, $3^{a}$ Edición, Marcial Pons, Madrid, 2010.

Grande, Elisabeta, "Dances of Criminal Justice, Thougths on Systemic Differences and the Search for the Truth", en JACKSON, John, y Otros, Crime, Procedure and Evidence in a Comparative and International Context, Essays in Honour of Professor Mirjan Damaska, Hart Publishing, Oxford, 2008.

Hendler, Edmundo, Derecho penal y procesal penal, Ed. Ad-Hoc, Buenos Aires, 1996.

Horvitz Lennon, María Inés; López MasLe, Julián, Derecho procesal penal chileno, Ed. Jurídica, Santiago, Tomos I y II, 2002 y 2004.

Igartúa Salaverría, Juan, El caso Marey. Presunción de inocencia y votos particulares, Trotta, Madrid, 1999.

Informe anual sobre Derechos Humanos en Chile en 2003 (hechos de 2002), Facultad de Derecho de la Universidad Diego Portales, Santiago, 2003.

Lafave, Wayne R.; ISRAel, Jerold H.; King, Nancy J., Criminal Procedure, $3{ }^{a}$ Edición, West Group, Saint Paul, MN, 2000.

LANGBEIN, John, The origins of adversary criminal trial, Oxford University Press, Oxford, 2005.

LaUdAN, Larry, "Por qué un estándar de prueba subjetivo y ambiguo no es un estándar", Traducción por Calvo Soler, Raúl, DOXA, Cuadernos de Filosofía del Derecho N²8, 2005.

LaUdAN, Truth, Error, and Criminal Law, and Essay in Legal Epistemology, Cambridge Studies in Philosophy and Law, Cambridge, 2006.

MAIER, Julio, Derecho procesal penal, $2^{\circ}$ Edición, Tomo I, Editores del Puerto, Buenos Aires, 2002. 
Maturana Miquel, Cristián (Coord.), Reforma Procesal Penal, Tomo II, Editorial Jurídica de Chile, Santiago, 2003.

MitTermaier, Kart Joseph, Tratado de la prueba en materia criminal, Traducción de González Del Alba, Primitivo, Hammurabi, Buenos Aires, 2006.

Muñoz Conde, Francisco, La búsqueda de la verdad en el proceso penal, $3^{a}$ Edición, Hammurabi, Buenos Aires, 2007.

PallLas, Enrique, Derecho procesal penal, Editorial Jurídica de Chile, Santiago, Volumen I, 1984.

Paillas, Enrique, La prueba en el proceso penal, Editorial Jurídica de Chile, Santiago, 1982.

Paredes Castañón, José Manuel; Rodríguez Montañés, Teresa, El caso de la colza, responsabilidad penal por productos adulterados o defectuosos, Tirant lo Blanch, Valencia,1995, passim.

Park, Roger; Leonard, David P.; GoldberG, Steven H., Evidence Law., West Group, Saint Paul, MN, 1998.

Pfefrer Urquiaga, Emilio, Código Procesal Penal. Anotado y concordado, Editorial Jurídica de Chile, Santiago, 2001.

Pızzı, William, Trials Without Truth, New York University Press, New York and London, 1999.

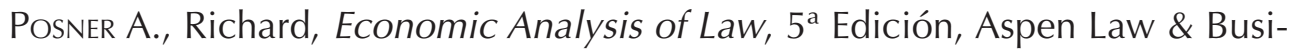
ness, 1998.

RıEGO, Cristián; DuCE, Mauricio, Introducción al nuevo sistema procesal penal, Volumen 1, Universidad Diego Portales, Santiago, 2002.

RieGo, Cristián, "Nuevo estándar de convicción", Informe de Investigación de la Facultad de Derecho de la Universidad Diego Portales № 17, 2003.

Ríos LaUlié, Francisco, "Estándar de convicción requerido para alcanzar una condena, propuesto en el nuevo Código Procesal Penal", en Seminario Reforma Procesal Penal. Universidad Católica de Temuco, 2001.

Rodríguez Fernández, Ricardo, Derechos fundamentales y garantías individuales en el proceso penal, Comares, Granada, 1999.

Roxın, Claus, Derecho procesal penal, 25 Edición Alemana, Trad. por Córdoba, Gabriela; Pastor, Daniel, Editores del Puerto, Buenos Aires, 2003.

Solan, Lawrence, "Refocusing the Burden of Proof in Criminal Cases, Some Doubt About Reasonable Doubt", Texas Law Review № 78, 1999.

TARUFFO, Michele, "Algunos comentarios sobre la valoración de la prueba", en: La Prueba, Artículos y Conferencias, Editorial Metropolitana, Santiago, 2009.

TARufFo, Michele, "Conocimiento Científico y Estándares de Prueba Judicial", en: La Prueba, Artículos y Conferencias, Editorial Metropolitana, Santiago, 2009. 
TARUFFO, Michele, "Tres observaciones sobre 'Por qué un estándar de prueba subjetivo y ambiguo no es un estándar', de Larry LAUDAN", Traducción de Ferrer Beltrán, Jordi, DOXA, Cuadernos de Filosofía del Derecho $N^{\circ} 28$, 2005.

Tortura, Derechos humanos y justicia criminal en Chile, Escuela de Derecho de la Universidad Diego Portales y Centro por la justicia y el Derecho Internacional, Santiago, 2002.

Urrutia Laubreaux, Daniel, "Aproximación al concepto de 'más allá de toda duda razonable' ", Boletín Centro de Estudios del Derecho, Universidad Católica del Norte № 2, 2002.

VázQuez Rossı, Jorge, Derecho procesal penal, Tomo II, Rubinzal-Culzoni, Buenos Aires, 1997.

Vegas Torres, Jaime, Presunción de inocencia y prueba en el proceso penal, La Ley, Madrid, 1993.

Vera, Robustiano, Código de Procedimiento Penal. Comentado y concordado. Imprenta El Debate, Santiago, 1906.

Verri, Pietro, "Observaciones sobre la tortura", citado por Carvalho, Salo de, Pena e Garantias, una leitura do garantismo de Luigi Ferrajoli no Brasil", Ed. Lumen Juris, Río de Janeiro.

Vial Campos, Pelayo, Técnicas y fundamentos del contraexamen en el proceso penal chileno, Ed. Librotecnia, Santiago, 2006.

VolokH, Alexander, "Better than ten guilty men...", en KING, Larry (Ed.), Beyond a Reasonable Doubt, Ed. Phoenix, California, 2006.

Whitman, James, The Origins of Reasonable Doubt, Theological roots of the criminal trial, Yale University Press, New Haven, 2008. 
